\title{
Nickel-Catalyzed Cycloaddition of Alkynes and Isocyanates
}

\author{
Hung A. Duong, Michael J. Cross, and Janis Louie* \\ Department of Chemistry, University of Utah, 315 South 1400 East, Salt Lake City, UT 84112-0850
}

\section{SUPPORTING INFORMATION}

General information. $\mathrm{Ni}(\mathrm{COD})_{2}$ was purschased from Strem and used without further purification. Tri-(n-butyl)-phosphine, tri-(tert-butyl)-phosphine, tricyclohexylphosphine and triphenylphosphine were purchased from Aldrich and used without further purification. 1,3-Bis-(2,4,6-trimethylphenyl)-imidazol2-ylidene (IMes), 1,3-bis-(2,6-diisopropylphenyl)-imidazol-2-ylidene (IPr), 1,3-dicyclohexylimidazol-2ylidene (ICy), 1,3-di-tert-butylimidazol-2-ylidene (ItBu), 1,3-diadamantylimidazol-2-ylidene (IAd), 1,3bis-(2,6-diisopropylphenyl)-imidazolin-2-ylidene (SIPr) were prepared according to literature procedures. ${ }^{1} \quad$ Phenyl isocyanate (2a), 4-methoxyphenyl isocyanate (2b), $\alpha, \alpha, \alpha$-trifluoro- $p$-tolyl isocyanate (2c), 2,6-dimethylphenyl isocyanate (2d), cyclohexyl isocyanate (2e) and butyl isocyanate (2f) were purchased from Aldrich, dried over phosphorous pentoxide, and degassed prior to use. 3,9Dodecadiyne (12), propargyl ether (16) and 3-hexyne, and 2,9-undecadiyne (22) were purchased from GFS chemicals, Aldrich and Lancaster, respectively, and were dried over calcium hydride, and degassed prior to use. Diynes 2,2-di-but-2-ynyl-malonic acid dimethyl ester (1), 2,2-bis-(4-methyl-pent-2-ynyl)malonic acid dimethyl ester (10), ${ }^{2} N, N$-di-2-butynyl- $p$-toluenesulfonamide (14), ${ }^{3}$ and 2,2-di-prop-2-ynylmalonic acid dimethyl ester $(\mathbf{1 8})^{4}$ were prepared according to literature procedures.

${ }^{1} \mathrm{H}$ and ${ }^{13} \mathrm{C}$ NMR spectra were recorded on a Varian VXL-300 spectrometer and a Varian VXR-500 spectrometer and referenced to residual protiated solvent (resonances downfield to the standard are reported as positive). All ${ }^{13} \mathrm{C}$ NMR spectra were proton decoupled. IR spectra were recorded on a Bruker Tensor 27 spectrometer. Elemental analyses were performed at Midwest Microlab LLC., Indianapolis, IN.

General co-cycloaddition procedure of internal diynes: A toluene solution of $\mathrm{Ni}(\mathrm{COD})_{2}$ and $\mathrm{SIPr}$ was prepared and allowed to equilibrate for at least $6 h^{2}{ }^{2}$ In a glove box, a solution of diyne and isocyanate in toluene was added to an oven-dried vial equipped with a stir bar. To the stirring solution, a solution of $\mathrm{Ni}(\mathrm{COD})_{2}$ and $\mathrm{SIPr}$ was added and the reaction was stirred at room temperature for 30 minutes (or until complete consumption of starting material was observed as judged by GC). The mixture was then concentrated and purified by silica gel column chromatography. This procedure was used for the cycloaddition unless otherwise noted.

2-Butyl-1,4-dimethyl-3-oxo-2,3,5,7-tetrahydro-[2]pyrindine-6,6-dicarboxylic acid dimethyl ester (3): The general procedure was used with diyne $1(200 \mathrm{mg}, 0.85 \mathrm{mmol}, 0.1 \mathrm{M})$, phenyl isocyanate $2 \mathrm{a}(100$ $\mathrm{mg}, 0.85 \mathrm{mmol}, 0.1 \mathrm{M}), \mathrm{Ni}(\mathrm{COD})_{2}(7.0 \mathrm{mg}, 0.025 \mathrm{mmol}, 3 \mathrm{~mol} \%)$, SIPr (9.8 mg, $\left.0.025 \mathrm{mmol}, 3 \mathrm{~mol} \%\right)$ and $8.5 \mathrm{~mL}$ of toluene. The reaction mixture was purified by column chromatography on silica gel (hexane/ethyl acetate 1:2) to afford 3 as a white solid (264 mg, $88 \%$ ). ${ }^{1} \mathrm{H}$ NMR (300 $\mathrm{MHz}, \mathrm{CDCl}_{3}, \mathrm{ppm}$ ): $\delta$ 7.62-7.52 (m, 3H), $7.25(\mathrm{~d}, 7.0 \mathrm{~Hz}, 2 \mathrm{H}), 3.90(\mathrm{~s}, 6 \mathrm{H}), 3.58(\mathrm{~s}, 2 \mathrm{H}), 3.50(\mathrm{~s}, 2 \mathrm{H}), 2.17(\mathrm{~s}, 3 \mathrm{H}), 1.96(\mathrm{~s}$, $3 \mathrm{H}) ;{ }^{13} \mathrm{C}\left\{{ }^{1} \mathrm{H}\right\}$ NMR $\left(125 \mathrm{MHz}, \mathrm{CDCl}_{3}, \mathrm{ppm}\right): \delta 171.8,164.2,150.3,139.7,136.3,129.8,128.6,128.3$, 121.0, 116.7, 59.5, 53.4, 39.6, 37.9, 18.5, 13.4; IR (KBr pellet): 1744, 1666, 1616, 1572; Anal. Calcd for $\mathrm{C}_{20} \mathrm{H}_{21} \mathrm{NO}_{5}$ : C, 67.59; H, 5.96; N, 3.94, found: C, 67.55; H, 5.99; N, 3.99 .

2-(4-Methoxy-phenyl)-1,4-dimethyl-3-oxo-2,3,5,7-tetrahydro-[2]pyrindine-6,6-dicarboxylic acid dimethyl ester (5): The general procedure was used with diyne 1 (100 $\mathrm{mg}, 0.42 \mathrm{mmol}, 0.1 \mathrm{M}), 4-$ 
methoxyphenyl isocyanate $\mathbf{2 b}(63 \mathrm{mg}, 0.42 \mathrm{mmol}, 0.1 \mathrm{M}), \mathrm{Ni}(\mathrm{COD})_{2}(3.5 \mathrm{mg}, 0.013 \mathrm{mmol}, 3 \mathrm{~mol} \%)$, SIPr (4.9 mg, $0.013 \mathrm{mmol}, 3 \mathrm{~mol} \%$ ) and $4.2 \mathrm{~mL}$ of toluene. The reaction mixture was purified by column chromatography on silica gel $(10 \%$ hexanes in ethyl acetate) to afford 5 as a white solid (140 mg, $86 \%$ ). ${ }^{1} \mathrm{H}$ NMR $\left(300 \mathrm{MHz}, \mathrm{CDCl}_{3}, \mathrm{ppm}\right): \delta 7.06$ (d, $\left.9.0 \mathrm{~Hz}, 2 \mathrm{H}\right), 6.99(\mathrm{~d}, 9.0 \mathrm{~Hz}, 2 \mathrm{H}), 3.85(\mathrm{~s}, 3 \mathrm{H}), 3.80$ $(\mathrm{s}, 6 \mathrm{H}), 3.47(\mathrm{~s}, 2 \mathrm{H}), 3.39(\mathrm{~s}, 2 \mathrm{H}), 2.07(\mathrm{~s}, 3 \mathrm{H}), 1.88(\mathrm{~s}, 3 \mathrm{H}) ;{ }^{13} \mathrm{C}\left\{{ }^{1} \mathrm{H}\right\} \mathrm{NMR}\left(125 \mathrm{MHz}, \mathrm{CDCl}_{3}, \mathrm{ppm}\right): \delta$ $171.8,164.5,159.5,150.1,136.8,132.4,129.2,120.8,116.5,115.0,59.5,55.7,53.4,39.5,37.9,18.5$, 13.4; IR (KBr pellet): 1730, 1666, 1614, 1574; Anal. Calcd for $\mathrm{C}_{21} \mathrm{H}_{23} \mathrm{NO}_{6}$ : C, 65.44; $\mathrm{H}, 6.02 ; \mathrm{N}, 3.63$, found: C, $65.39 ; \mathrm{H}, 6.15 ; \mathrm{N}, 3.72$.

1,4-Dimethyl-3-oxo-2-(4-trifluoromethyl-phenyl)-2,3,5,7-tetrahydro-[2]pyrindine-6,6-dicarboxylic acid dimethyl ester (6): In a glove box, a solution of diyne $1(50 \mathrm{mg}, 0.21 \mathrm{mmol}, 0.1 \mathrm{M})$ and $\alpha, \alpha, \alpha-$ trifluoro- $p$-tolyl isocyanate $2 \mathrm{c}(40 \mathrm{mg}, 0.21 \mathrm{mmol}, 0.1 \mathrm{M})$ in toluene $(1.3 \mathrm{~mL})$ was added to an oven dried screw-cap vial. The vial was removed from the glove box and heated in an oil bath at $80{ }^{\circ} \mathrm{C}$ for several minutes. A solution of $\mathrm{Ni}(\mathrm{COD})_{2}(2.9 \mathrm{mg}, 0.011 \mathrm{mmol}, 5 \mathrm{~mol} \%)$ and SIPr $(4.1 \mathrm{mg}, 0.011 \mathrm{mmol}, 5 \mathrm{~mol}$ $\%)$ in toluene $(0.8 \mathrm{~mL})$ was added via syringe and the reaction was heated for 30 minutes. The mixture was then concentrated and purified by chromatography on silica gel (hexane/ethyl acetate 1:2) to afford 6 as a white solid (75 mg, $84 \%) .{ }^{1} \mathrm{H}$ NMR $\left(300 \mathrm{MHz}, \mathrm{CDCl}_{3}, \mathrm{ppm}\right): \delta 7.78(\mathrm{~d}, 8.2 \mathrm{~Hz}, 2 \mathrm{H}), 7.31(\mathrm{~d}, 8.2 \mathrm{~Hz}$, $2 \mathrm{H}), 3.81(\mathrm{~s}, 6 \mathrm{H}), 3.49(\mathrm{~s}, 2 \mathrm{H}), 3.40(\mathrm{~s}, 2 \mathrm{H}), 2.08(\mathrm{~s}, 3 \mathrm{H}), 1.86(\mathrm{~s}, 3 \mathrm{H}) ;{ }^{13} \mathrm{C}\left\{{ }^{1} \mathrm{H}\right\} \mathrm{NMR}\left(125 \mathrm{MHz}, \mathrm{CDCl}_{3}\right.$, ppm): $\delta 171.7,164.0,150.8,142.9,135.6,131.0\left(\mathrm{q}, \mathrm{J}^{2}(\mathrm{C}, \mathrm{F})=33.0 \mathrm{~Hz}\right), 129.1,127.0,124.0\left(\mathrm{q}, \mathrm{J}^{1}(\mathrm{C}, \mathrm{F})=\right.$ $272.3 \mathrm{~Hz}$ ), 121.3, 117.2, 59.5, 53.5, 39.6, 37.8, 18.5, 13.4; IR (KBr pellet): 1740, 1671, 1620, 1579; Anal. Calcd for $\mathrm{C}_{21} \mathrm{H}_{20} \mathrm{~F}_{3} \mathrm{NO}_{5}$ : C, 59.57; H, 4.76; N, 3.31, found: C, 59.43; H, 4.87; N, 3.22.

2-(2,6-Dimethyl-phenyl)-1,4-dimethyl-3-oxo-2,3,5,7-tetrahydro-[2]pyrindine-6,6-dicarboxylic acid dimethyl ester (7): The general procedure was used with diyne 1 (50 mg, $0.21 \mathrm{mmol}, 0.1 \mathrm{M}), 2,6$ dimethylphenyl isocyanate $\mathbf{2 d}(31 \mathrm{mg}, 0.21 \mathrm{mmol}, 0.1 \mathrm{M}), \mathrm{Ni}(\mathrm{COD})_{2}(1.7 \mathrm{mg}, 0.006 \mathrm{mmol}, 3 \mathrm{~mol} \%)$, SIPr $(2.4 \mathrm{mg}, 0.006 \mathrm{mmol}, 3 \mathrm{~mol} \%)$ and $4.2 \mathrm{~mL}$ of toluene. The reaction was complete after 2 hours as monitored by gas chromatography. The reaction mixture was purified by column chromatography on silica gel (10\% hexanes in diethyl ether) to afford 7 as a white solid $(67 \mathrm{~g}, 83 \%)$. ${ }^{1} \mathrm{H} \mathrm{NMR}(300 \mathrm{MHz}$, $\left.\mathrm{CDCl}_{3}, \mathrm{ppm}\right): \delta$ 7.24-7.13 (m, 3H), $3.80(6 \mathrm{H}), 3.51(\mathrm{~s}, 2 \mathrm{H}), 3.42(\mathrm{~s}, 2 \mathrm{H}), 2.08(\mathrm{~s}, 3 \mathrm{H}), 1.99(\mathrm{~s}, 6 \mathrm{H}), 1.76$ $(\mathrm{s}, 3 \mathrm{H}) ;{ }^{13} \mathrm{C}\left\{{ }^{1} \mathrm{H}\right\} \mathrm{NMR}\left(125 \mathrm{MHz}, \mathrm{CDCl}_{3}, \mathrm{ppm}\right): \delta 171.8,162.8,150.5,138.0,135.7,135.1,128.8,128.6$, 121.0, 117.0, 59.5, 53.4, 39.6, 37.9, 17.9, 17.1, 13.4; IR (KBr pellet): 1734, 1667, 1614, 1578; Anal. Calcd for $\mathrm{C}_{22} \mathrm{H}_{25} \mathrm{NO}_{5}$ : C, 68.91; H, 6.57; N, 3.65, found: C, 68.77; H, 6.61; N, 3.62.

2-Cyclohexyl-1,4-dimethyl-3-oxo-2,3,5,7-tetrahydro-[2]pyrindine-6,6-dicarboxylic acid dimethyl ester (8): The general procedure was used with diyne 1 (50 $\mathrm{mg}, 0.21 \mathrm{mmol}, 0.1 \mathrm{M})$, cyclohexyl isocyanate $2 \mathrm{e}(27 \mathrm{mg}, 0.21 \mathrm{mmol}, 0.1 \mathrm{M}), \mathrm{Ni}(\mathrm{COD})_{2}(1.7 \mathrm{mg}, 0.006 \mathrm{mmol}, 3 \mathrm{~mol} \%), \operatorname{SIPr}(2.4 \mathrm{mg}, 0.006$ mmol, $3 \mathrm{~mol} \%$ ) and $4.2 \mathrm{~mL}$ of toluene. The reaction mixture was purified by column chromatography on silica gel (hexane/diethyl ether $1: 1)$ to afford 8 as a white solid $(70 \mathrm{mg}, 91 \%)$. ${ }^{1} \mathrm{H}$ NMR $(300 \mathrm{MHz}$, $\left.\mathrm{CDCl}_{3}, \mathrm{ppm}\right): \delta 3.90-3.77(\mathrm{~m}, 7 \mathrm{H}), 3.39-3.37(\mathrm{~m}, 4 \mathrm{H}), 2.91-2.88(\mathrm{~m}, 2 \mathrm{H}), 2.26(\mathrm{~s}, 3 \mathrm{H}), 2.00(\mathrm{~s}, 3 \mathrm{H}), 1.88$ $(\mathrm{m}, 2 \mathrm{H}), 1.62-1.58(\mathrm{~m}, 3 \mathrm{H}), 1.30-1.28(3 \mathrm{H}) ;{ }^{13} \mathrm{C}\left\{{ }^{1} \mathrm{H}\right\} \mathrm{NMR}\left(125 \mathrm{MHz}, \mathrm{CDCl}_{3}, \mathrm{ppm}\right): \delta 171.9,164.5$, 148.6, 136.0, 121.9, 117.2, 60.6, 59.4, 53.4, 39.4, 38.6, 28.4, 26.8, 25.4, 18.1, 13.4; IR (KBr pellet): 1742, 1670, 1619, 1582; Anal. Calcd for $\mathrm{C}_{20} \mathrm{H}_{27} \mathrm{NO}_{5}: \mathrm{C}, 66.46 ; \mathrm{H}, 7.53 ; \mathrm{N}, 3.88$, found: C, 66.63; H, 7.73; N, 3.98 .

2-Butyl-1,4-dimethyl-3-oxo-2,3,5,7-tetrahydro-[2]pyrindine-6,6-dicarboxylic acid dimethyl ester (9): The general procedure was used with diyne 1 (50 $\mathrm{mg}, 0.21 \mathrm{mmol}, 0.1 \mathrm{M})$, butyl isocyanate $\mathbf{2 f}(42 \mathrm{mg}$, $0.21 \mathrm{mmol}, 0.1 \mathrm{M}), \mathrm{Ni}(\mathrm{COD})_{2}(1.7 \mathrm{mg}, 0.006 \mathrm{mmol}, 3 \mathrm{~mol} \%)$, SIPr $(2.4 \mathrm{mg}, 0.006 \mathrm{mmol}, 3 \mathrm{~mol} \%)$ and $4.2 \mathrm{~mL}$ of toluene. The reaction mixture was purified by column chromatography on silica gel (diethyl ether) to afford 9 as a white solid $(67 \mathrm{mg}, 94 \%)$. ${ }^{1} \mathrm{H}$ NMR $\left(300 \mathrm{MHz}, \mathrm{CDCl}_{3}, \mathrm{ppm}\right): \delta 3.97(\mathrm{t}, 8.0 \mathrm{~Hz}$, 2H), $3.77(\mathrm{~s}, 6 \mathrm{H}), 3.41(\mathrm{~s}, 2 \mathrm{H}), 3.37(\mathrm{~s}, 2 \mathrm{H}), 2.28(\mathrm{~s}, 3 \mathrm{H}), 2.04(\mathrm{~s}, 3 \mathrm{H}), 1.68-1.57(\mathrm{~m}, 2 \mathrm{H}), 1.48-1.35(\mathrm{~m}$, $2 \mathrm{H}), 0.96(\mathrm{t}, 7.3 \mathrm{~Hz}, 3 \mathrm{H}) ;{ }^{13} \mathrm{C}\left\{{ }^{1} \mathrm{H}\right\}$ NMR $\left(125 \mathrm{MHz}, \mathrm{CDCl}_{3}, \mathrm{ppm}\right): \delta 171.8,163.6,149.1,136.0,120.3$, 116.9, 59.4, 53.4, 44.9, 39.5, 38.2, 30.9, 20.6, 17.2, 14.0, 13.6; IR (KBr pellet): 1732, 1664, 1610, 1587; Anal. Calcd for $\mathrm{C}_{18} \mathrm{H}_{25} \mathrm{NO}_{5}$ : C, 64.46; H, 7.51; N, 4.18, found: C, 64.34; H, 7.63, N, 4.12. 
Dimethyl

2-butyl-2,3-dihydro-1,4-diisopropyl-3-oxo-5H-cyclopenta[c]pyridine-6,6(7H)dicarboxylate (11): The general procedure was used with diyne 10 (47 $\mathrm{mg}, 0.16 \mathrm{mmol}, 0.1 \mathrm{M})$, butyl isocyanate $2 \mathrm{f}(16 \mathrm{mg}, 0.16 \mathrm{mmol}, 0.1 \mathrm{M}), \mathrm{Ni}(\mathrm{COD})_{2}(2.2 \mathrm{mg}, 0.008 \mathrm{mmol}, 5 \mathrm{~mol} \%)$, SIPr $(3.1 \mathrm{mg}, 0.008$ mmol, $5 \mathrm{~mol} \%$ ) and $1.6 \mathrm{~mL}$ of toluene. The reaction mixture was purified by column chromatography on silica gel (hexane/ethyl acetate $1: 1)$ to afford 11 as a colorless oil $(54 \mathrm{mg}, 86 \%)$. ${ }^{1} \mathrm{H}$ NMR $(300 \mathrm{MHz}$, $\left.\mathrm{CDCl}_{3}, \mathrm{ppm}\right): \delta 4.00(\mathrm{~s}, 2 \mathrm{H}), 3.76(\mathrm{~s}, 6 \mathrm{H}), 3.42(\mathrm{~s}, 2 \mathrm{H}), 3.41(\mathrm{~s}, 2 \mathrm{H}), 3.24-3.12(\mathrm{~m}, 2 \mathrm{H})$, 1.64-1.56 (m, 2H), 1.48-1.25 (m, 14H), $0.97(\mathrm{t}, 2.4 \mathrm{~Hz}, 3 \mathrm{H}) ;{ }^{13} \mathrm{C}\left\{{ }^{1} \mathrm{H}\right\} \mathrm{NMR}\left(125 \mathrm{MHz}, \mathrm{CDCl}_{3}, \mathrm{ppm}\right): \delta 171.6,162.4$, $149.2,146.2,129.3,115.5,60.4,53.3,44.6,38.5,38.0,32.0,30.2,28.8,20.5,20.4,20.2,14.0$; IR $\left(\mathrm{CHCl}_{3}\right): 1738,1651,1564$; Anal. Calcd for $\mathrm{C}_{22} \mathrm{H}_{33} \mathrm{NO}_{5}: \mathrm{C}, 67.49 ; \mathrm{H}, 8.50 ; \mathrm{N}, 3.58$, found: $\mathrm{C}, 67.55 ; \mathrm{H}$, $8.31 ; \mathrm{N}, 3.61$.

2-Cyclohexyl-1,4-diethyl-5,6,7,8-tetrahydro-2H-isoquinolin-3-one (13): The general procedure was used with diyne $12(200 \mathrm{mg}, 1.23 \mathrm{mmol}, 0.1 \mathrm{M})$, cyclohexyl isocyanate $2 \mathrm{e}(154 \mathrm{mg}, 1.23 \mathrm{mmol}, 0.1 \mathrm{M})$, $\mathrm{Ni}(\mathrm{COD})_{2}(10.2 \mathrm{mg}, 0.037 \mathrm{mmol}, 3 \mathrm{~mol} \%)$, SIPr $(14.4 \mathrm{mg}, 0.037 \mathrm{mmol}, 3 \mathrm{~mol} \%)$ and $12.3 \mathrm{~mL}$ of toluene. The reaction mixture was purified by column chromatography on silica gel (hexane/ethyl acetate 3:1) to afford 13 as a white solid (348 mg, $98 \%)$. ${ }^{1} \mathrm{H}$ NMR $\left(300 \mathrm{MHz}, \mathrm{CDCl}_{3}, \mathrm{ppm}\right): \delta 3.94(\mathrm{t}, 11.3 \mathrm{~Hz}$, $1 \mathrm{H}), 3.02(\mathrm{q}, 12.2 \mathrm{~Hz}, 2 \mathrm{H}), 2.64-1.90(\mathrm{~m}, 8 \mathrm{H}), 1.90-1.87(\mathrm{~m}, 2 \mathrm{H}), 1.72-1.58(\mathrm{~m}, 7 \mathrm{H}), 1.37-1.26(\mathrm{~m}, 3 \mathrm{H})$, $1.18(\mathrm{t}, 7.5 \mathrm{~Hz}, 3 \mathrm{H}), 1.06(\mathrm{t}, 7.5 \mathrm{~Hz}, 3 \mathrm{H}) ;{ }^{13} \mathrm{C}\left\{{ }^{1} \mathrm{H}\right\} \mathrm{NMR}\left(125 \mathrm{MHz}, \mathrm{CDCl}_{3}, \mathrm{ppm}\right): \delta 162.6,145.3,143.8$, 130.1, 113.1, 60.5, 28.8, 27.2, 26.9, 26.4, 25.5, 23.4, 22.6, 22.5, 19.8, 13.0, 12.6; IR (KBr pellet): 1634, 1580, 1568, 1529, 1455; Anal. Calcd for $\mathrm{C}_{19} \mathrm{H}_{29} \mathrm{NO}$ : C, 79.39; H, 10.17; N, 4.87, found: C, 79.32; H, $10.24 ; \mathrm{N}, 4.91$.

4,7-Dimethyl-5-phenyl-2-(toluene-4-sulfonyl)-1,2,3,5-tetrahydro-pyrrolo[3,4-c]pyridin-6-one (15): The general procedure was used with diyne $14(100 \mathrm{mg}, 0.36 \mathrm{mmol}, 0.1 \mathrm{M})$, phenyl isocyanate $2 \mathrm{a}$ (43 $\mathrm{mg}, 0.36 \mathrm{mmol}, 0.1 \mathrm{M}), \mathrm{Ni}(\mathrm{COD})_{2}(3.0 \mathrm{mg}, 0.011 \mathrm{mmol}, 3 \mathrm{~mol} \%)$, SIPr (4.2 mg, $\left.0.011 \mathrm{mmol}, 3 \mathrm{~mol} \%\right)$ and $3.6 \mathrm{~mL}$ of toluene. The reaction mixture was purified by column chromatography on silica gel (hexane/ethyl acetate 1:4) afford 15 as white solid (112 mg, $78 \%$ ). $\left.{ }^{1} \mathrm{H} \mathrm{NMR} \mathrm{(300} \mathrm{MHz,} \mathrm{CDCl}_{3}, \mathrm{ppm}\right): \delta$ $7.80(\mathrm{~d}, 8.2 \mathrm{~Hz}, 2 \mathrm{H}), 7.51-7.36(\mathrm{~m}, 5 \mathrm{H}), 7.09(\mathrm{~d}, 7.0 \mathrm{~Hz}, 2 \mathrm{H}), 4.44(\mathrm{~s}, 2 \mathrm{H}), 4.40(\mathrm{~s}, 2 \mathrm{H}), 2.45$ (s, 3H), 2.00 $(\mathrm{s}, 3 \mathrm{H}), 1.80(\mathrm{~s}, 3 \mathrm{H}) ;{ }^{13} \mathrm{C}\left\{{ }^{1} \mathrm{H}\right\} \mathrm{NMR}\left(125 \mathrm{MHz}, \mathrm{CDCl}_{3}, \mathrm{ppm}\right): \delta 163.9,146.2,144.3,139.0,136.3,133.5$, 130.2, 130.0, 129.0, 128.1, 127.9, 120.2, 113.4, 52.5, 51.4, 21.8, 18.5, 13.4; IR (KBr pellet): 1675, 1625, 1582; Anal. Calcd for $\mathrm{C}_{22} \mathrm{H}_{22} \mathrm{~N}_{2} \mathrm{O}_{3} \mathrm{~S}$ : C, 66.98; H, 5.62; N, 7.10, found: C, 66.75; H, 5.84; N, 6.87 .

5-Phenyl-3,5-dihydro-1H-furo[3,4-c]pyridine-6-one (17): ${ }^{5}$ In a glove box, a solution of $\mathrm{Ni}(\mathrm{COD})_{2}$ $(7.0 \mathrm{mg}, 0.025 \mathrm{mmol}, 5 \mathrm{~mol} \%)$ and SIPr $(9.9 \mathrm{mg}, 0.025 \mathrm{mmol}, 5 \mathrm{~mol} \%)$ in toluene $(2.1 \mathrm{~mL})$ was added to an oven dried vial. To the stirring solution, a solution of propargyl ether 16 (48 $\mathrm{mg}, 0.51 \mathrm{mmol}, 0.05$ M) and phenyl isocyanate $2 \mathrm{a}(61 \mathrm{mg}, 0.51 \mathrm{mmol}, 0.05 \mathrm{M})$ was added slowly over one minute and the reaction was stirred at room temperature for 30 minutes. The reaction was concentrated and the residue was purified by column chromatography on silica gel (ethyl acetate/hexane 4:1) to afford a yellowish solid (42 mg, $39 \%$ ). This solid was dissolved in $5 \mathrm{~mL}$ of methanol, stirred with a small amount of charcoal for several minutes, filtered and concentrated. The resulting solid was recrystallized in $\mathrm{CH}_{2} \mathrm{Cl}_{2}$ /hexane to afford 17 as a white solid (34 mg, $31 \%$ ). $\left.{ }^{1} \mathrm{H} \mathrm{NMR} \mathrm{(300} \mathrm{MHz,} \mathrm{CDCl}_{3}, \mathrm{ppm}\right)$ : $\delta$ 7.51$7.37(\mathrm{~m}, 5 \mathrm{H}), 7.26(\mathrm{~s}, 1 \mathrm{H}), 6.52(\mathrm{~s}, 1 \mathrm{H}), 4.93(\mathrm{~s}, 2 \mathrm{H}), 4.90(\mathrm{~s}, 2 \mathrm{H}) ;{ }^{13} \mathrm{C}\left\{{ }^{1} \mathrm{H}\right\} \mathrm{NMR}\left(125 \mathrm{MHz}, \mathrm{CDCl}_{3}\right.$, ppm): $\delta 162.4,155.3,141.4,129.8,129.6,128.7,126.8,119.1,112.3,71.8,70.0$; IR (KBr pellet): 1686, 1616.

3-Oxo-2-phenyl-2,3,5,7-tetrahydro-[2]pyrindine-6,6-dicarboxylic acid dimethyl ester (19): ${ }^{5}$ In a glove box, a solution of $\mathrm{Ni}(\mathrm{COD})_{2}(3.3 \mathrm{mg}, 0.012 \mathrm{mmol}, 5 \mathrm{~mol} \%)$ and SIPr (4.7 $\mathrm{mg}, 0.012 \mathrm{mmol}, 5 \mathrm{~mol}$ $\%)$ in toluene $(0.95 \mathrm{~mL})$ was added to an oven dried vial. To the stirring solution, phenyl isocyanate $\mathbf{2 a}$ $(115 \mathrm{mg}, 0.96 \mathrm{mmol}, 0.20 \mathrm{M})$ was added followed by slow addition of a solution of diyne 18 (50 $\mathrm{mg}, 0.24$ mmol, $0.05 \mathrm{M})$ in toluene $(3.8 \mathrm{~mL})$ over one minute and the reaction was stirred at room temperature for 30 minutes. The reaction was concentrated and the residue was purified by column chromatography on silica gel (ethyl acetate) to afford 19 as a white solid (57 mg, $72 \%)$. ${ }^{1} \mathrm{H} \mathrm{NMR}\left(500 \mathrm{MHz}, \mathrm{CDCl}_{3}, \mathrm{ppm}\right): \delta$ 7.49-7.35 (m, 5H), $7.18(\mathrm{~s}, 1 \mathrm{H}), 6.51(\mathrm{~s}, 1 \mathrm{H}), 3.79(\mathrm{~s}, 6 \mathrm{H}), 3.48(\mathrm{~d}, 1.0 \mathrm{~Hz}, 2 \mathrm{H}), 3.38(\mathrm{~d}, 0.9 \mathrm{~Hz}, 2 \mathrm{H})$; ${ }^{13} \mathrm{C}$ 
$\left\{{ }^{1} \mathrm{H}\right\} \mathrm{NMR}\left(125 \mathrm{MHz}, \mathrm{CDCl}_{3}, \mathrm{ppm}\right): \delta 171.3,162.5,155.9,141.5,132.0,129.5,128.5,126.9,119.3$, 115.6, 60.8, 53.5, 40.0, 36.7; IR (KBr pellet): 1736, 1682, 1621, 1269.

2-Cyclohexyl-3-oxo-2,3,5,7-tetrahydro-[2]pyrindine-6,6-dicarboxylic acid dimethyl ester (20): ${ }^{5}$ In a glove box, a solution of $\mathrm{Ni}(\mathrm{COD})_{2}(3.3 \mathrm{mg}, 0.012 \mathrm{mmol}, 5 \mathrm{~mol} \%)$ and SIPr $(4.7 \mathrm{mg}, 0.012 \mathrm{mmol}, 5 \mathrm{~mol}$ $\%)$ in toluene $(0.95 \mathrm{~mL})$ was added to an oven dried vial. To the stirring solution, cyclohexyl isocyanate 2e $(120 \mathrm{mg}, 0.96 \mathrm{mmol}, 0.20 \mathrm{M})$ was added followed by slow addition of a solution of diyne $18(50 \mathrm{mg}$, $0.24 \mathrm{mmol}, 0.05 \mathrm{M})$ in toluene $(3.8 \mathrm{~mL})$ over one minute and the reaction was stirred at room temperature for 30 minutes. The reaction was concentrated and the residue was purified by column chromatography on silica gel (ethyl acetate) to afford 20 as a white solid (62 mg, $77 \%)$. ${ }^{1} \mathrm{H}$ NMR (300 $\mathrm{MHz}, \mathrm{CDCl}_{3}$, ppm): $\delta 7.17(\mathrm{~s}, 1 \mathrm{H}), 6.41(\mathrm{~s}, 1 \mathrm{H}), 4.91-4.82(\mathrm{~m}, 1 \mathrm{H}), 3.77(\mathrm{~s}, 6 \mathrm{H}), 3.41(\mathrm{~d}, 1.1 \mathrm{~Hz}, 2 \mathrm{H}), 3.36(\mathrm{~s}, 2 \mathrm{H})$, $1.92-1.15(\mathrm{~m}, 10 \mathrm{H}) ;{ }^{13} \mathrm{C}\left\{{ }^{1} \mathrm{H}\right\} \mathrm{NMR}\left(125 \mathrm{MHz}, \mathrm{CDCl}_{3}, \mathrm{ppm}\right): \delta 171.4,162.3,154.0,127.5,119.1,114.5$, 60.8, 53.9, 53.4, 40.0, 37.1, 33.0, 26.0, 25.7; IR (KBr pellet): 1738, 1677, 1596.

2-Benzyl-3-oxo-2,3,5,7-tetrahydro-[2]pyrindine-6,6-dicarboxylic acid dimethyl ester (21): ${ }^{5}$ In a glove box, a solution of $\mathrm{Ni}(\mathrm{COD})_{2}(3.3 \mathrm{mg}, 0.012 \mathrm{mmol}, 5 \mathrm{~mol} \%)$ and $\mathrm{SIPr}(4.7 \mathrm{mg}, 0.012 \mathrm{mmol}, 5 \mathrm{~mol}$ $\%)$ in toluene $(0.95 \mathrm{~mL})$ was added to an oven dried vial. To the stirring solution, a solution of diyne 18 $(50 \mathrm{mg}, 0.24 \mathrm{mmol}, 0.05 \mathrm{M})$ and benzyl isocyanate $2 \mathrm{~g}(32 \mathrm{mg}, 0.24 \mathrm{mmol}, 0.05 \mathrm{M})$ was added slowly over one minute and the reaction was stirred at room temperature for 30 minutes. The reaction was concentrated and the residue was purified by column chromatography on silica gel (ethyl acetate/hexane $4: 1)$ to afford a yellowish solid $(51 \mathrm{mg}, 62 \%)$, which is pure as observed by ${ }^{1} \mathrm{H}$ NMR. This solid was dissolved in $5 \mathrm{~mL}$ of methanol and stirred with a small amount of charcoal for several minutes. The solution was filtered and concentrated in vacuo to afford 21 as a white solid (50 mg, 61\%). ${ }^{1} \mathrm{H}$ NMR (300 MHz, $\left.\mathrm{CDCl}_{3}, \mathrm{ppm}\right): \delta$ 7.31-7.24 (m, 5H), $7.08(\mathrm{~s}, 1 \mathrm{H}), 6.43(\mathrm{~s}, 1 \mathrm{H}), 5.05(\mathrm{~s}, 2 \mathrm{H}), 3.71(\mathrm{~s}, 6 \mathrm{H}), 3.38$ $(\mathrm{d}, 1.2 \mathrm{~Hz}, 2 \mathrm{H}), 3.26(\mathrm{~d}, 1.0 \mathrm{~Hz}, 2 \mathrm{H}) ;{ }^{13} \mathrm{C}\left\{{ }^{1} \mathrm{H}\right\} \mathrm{NMR}\left(125 \mathrm{MHz}, \mathrm{CDCl}_{3}, \mathrm{ppm}\right): \delta 171.5,162.6,155.3$, 136.7, 131.1, 128.9, 128.3, 128.0, 119.5, 114.8, 60.7, 53.3, 52.0, 39.9, 36.7; IR (KBr pellet): 1737, 1672, 1601.

2-Butyl-1,4-dimethyl-2,5,6,7,8,9-hexahydro-cyclohepta[c]pyridine-3-one (23): In a glove box, a solution of $\mathrm{Ni}(\mathrm{COD})_{2}(4.8 \mathrm{mg}, 0.018 \mathrm{mmol}, 5 \mathrm{~mol} \%)$ and $\mathrm{SIPr}(6.8 \mathrm{mg}, 0.018 \mathrm{mmol}, 5 \mathrm{~mol} \%)$ in toluene $(1.4 \mathrm{~mL})$ was added to an oven dried screw-cap vial. The vial was removed from the glove box and heated in an oil bath at $80^{\circ} \mathrm{C}$ minutes for several minutes. To the stirring solution, a solution of diyne $22(52 \mathrm{mg}$, $0.35 \mathrm{mmol}, 0.05 \mathrm{M})$ and butyl isocyanate $2 \mathrm{f}(35 \mathrm{mg}, 0.35 \mathrm{mmol}, 0.05 \mathrm{M})$ in toluene $(5.6 \mathrm{~mL})$ was added slowly over one minute via syringe. After 30 minutes, the solvent was removed in vacuo and the residue was purified by chromatography on silica gel (hexane/ether 1:5) to afford $\mathbf{2 3}$ as a white solid (32 $\mathrm{mg}, 37$ \%). ${ }^{1} \mathrm{H}$ NMR $\left(300 \mathrm{MHz}, \mathrm{CDCl}_{3}, \mathrm{ppm}\right): \delta 4.07(\mathrm{t}, 7.9 \mathrm{~Hz}, 2 \mathrm{H}), 2.72(\mathrm{t}, 5.2 \mathrm{~Hz}, 2 \mathrm{H}), 2.63(\mathrm{t}, 5.2 \mathrm{~Hz}, 2 \mathrm{H})$, $2.35(\mathrm{~s}, 3 \mathrm{H}), 2.15(\mathrm{~s}, 3 \mathrm{H}), 1.72-1.40(\mathrm{~m}, 10 \mathrm{H}), 0.97(\mathrm{t}, 7.2 \mathrm{~Hz}, 3 \mathrm{H}) ;{ }^{13} \mathrm{C}\left\{{ }^{1} \mathrm{H}\right\} \mathrm{NMR}\left(125 \mathrm{MHz}, \mathrm{CDCl}_{3}\right.$, ppm): $\delta 163.0,151.8,136.4,121.9,120.1,45.4,31.0,30.9,30.7,29.0,28.5,27.2,20.6,16.1,14.0,13.1$; IR $\left(\mathrm{CHCl}_{3}\right): 1639,1588,1543$; Anal. Calcd for $\mathrm{C}_{16} \mathrm{H}_{25} \mathrm{NO}: \mathrm{C}, 77.68 ; \mathrm{H}, 10.19 ; \mathrm{N}, 5.66$, found: $\mathrm{C}$, 77.69; $\mathrm{H}, 10.07 ; \mathrm{N}, 5.58$.

3,4,5,6-Tetraethyl-1-phenyl-1H-pyridine-2-one (24): ${ }^{6}$ In a glove box, a solution of 3-hexyne (50 mg, $0.61 \mathrm{mmol}, 0.1 \mathrm{M})$ and phenyl isocyanate $2 \mathrm{a}(73 \mathrm{mg}, 0.61 \mathrm{mmol}, 0.1 \mathrm{M})$ in toluene $(4.7 \mathrm{~mL})$ was added to an oven dried vial. To the stirring solution, a solution of $\mathrm{Ni}(\mathrm{COD})_{2}(5.0 \mathrm{mg}, 0.018 \mathrm{mmol}, 3 \mathrm{~mol} \%)$ and SIPr ( $7.0 \mathrm{mg}, 0.018 \mathrm{mmol}, 3 \mathrm{~mol} \%)$ in toluene $(1.5 \mathrm{~mL})$ was added. After 30 minutes, the solvent was removed in vacuo and the residue was purified by column chromatography (ether) to give colorless oil. Recrystallization from hexane gave $\mathbf{2 4}$ as a white solid $(78 \mathrm{mg}, 90 \%)$. ${ }^{1} \mathrm{H} \mathrm{NMR} \mathrm{(300} \mathrm{MHz}, \mathrm{CDCl}_{3}$, ppm): $\delta$ 7.52-7.21 (m, 5H), 2.63-2.57 (m, 4H), $2.49(\mathrm{q}, 7.5 \mathrm{~Hz}, 2 \mathrm{H}), 2.36(\mathrm{q}, 7.5 \mathrm{~Hz}, 2 \mathrm{H}), 1.21-1.15(\mathrm{~m}$, 9H), 0.95 (t, $7.5 \mathrm{~Hz}, 3 \mathrm{H}) ;{ }^{13} \mathrm{C}\left\{{ }^{1} \mathrm{H}\right\} \mathrm{NMR}\left(125 \mathrm{MHz}, \mathrm{CDCl}_{3}, \mathrm{ppm}\right): \delta 163.0,151.6,144.3,140.0,130.0$, 129.4, 128.7, 128.2, 117.7, 23.2, 22.6, 21.0, 20.7, 16.1, 15.0, 14.0, 13.7; IR (KBr pellet): 1642, 1579, 1529; Anal. Calcd for $\mathrm{C}_{19} \mathrm{H}_{25} \mathrm{NO}$ : C, 80.52; H, 8.89; N, 4.94, found: C, 80.64, H, 9.28; N, 4.90. 


\section{References}

(1) (a) Arduengo, A. J. III; Krafczyk, R.; Schmutzler, R.; Craig, H. A.; Goerlich, J. R.; Marshall, W. J. Unverzagt, M. Tetrahedron 1999, 55, 14523. (b) Bohm, V. P. W.; Weskammp, T.; Gstottmayr, W. K.; Herrmann, W. A. Angew. Chem. Int. Ed. 2000, 39, 1602.

(2) Louie, J.; Gibby, J. E.; Farnworth, M. V.; Tekavec, T. N. J. Am. Chem. Soc. 2002, 124, 15188.

(3) Nishida, M.; Shiga, H.; Mori, M. J. Org. Chem. 1998, 63, 8606.

(4) Atkinson, R. S.; Grimshire, M. J. J. Chem. Soc. Perkin Trans. 1 1986, 1215.

(5) Yamamoto, Y.; Takagishi, H.; Itoh, K. Org. Lett. 2001, 3, 2117.

(6) Hoberg, H.; Oster, B. W. Synthesis 1982, 324. 

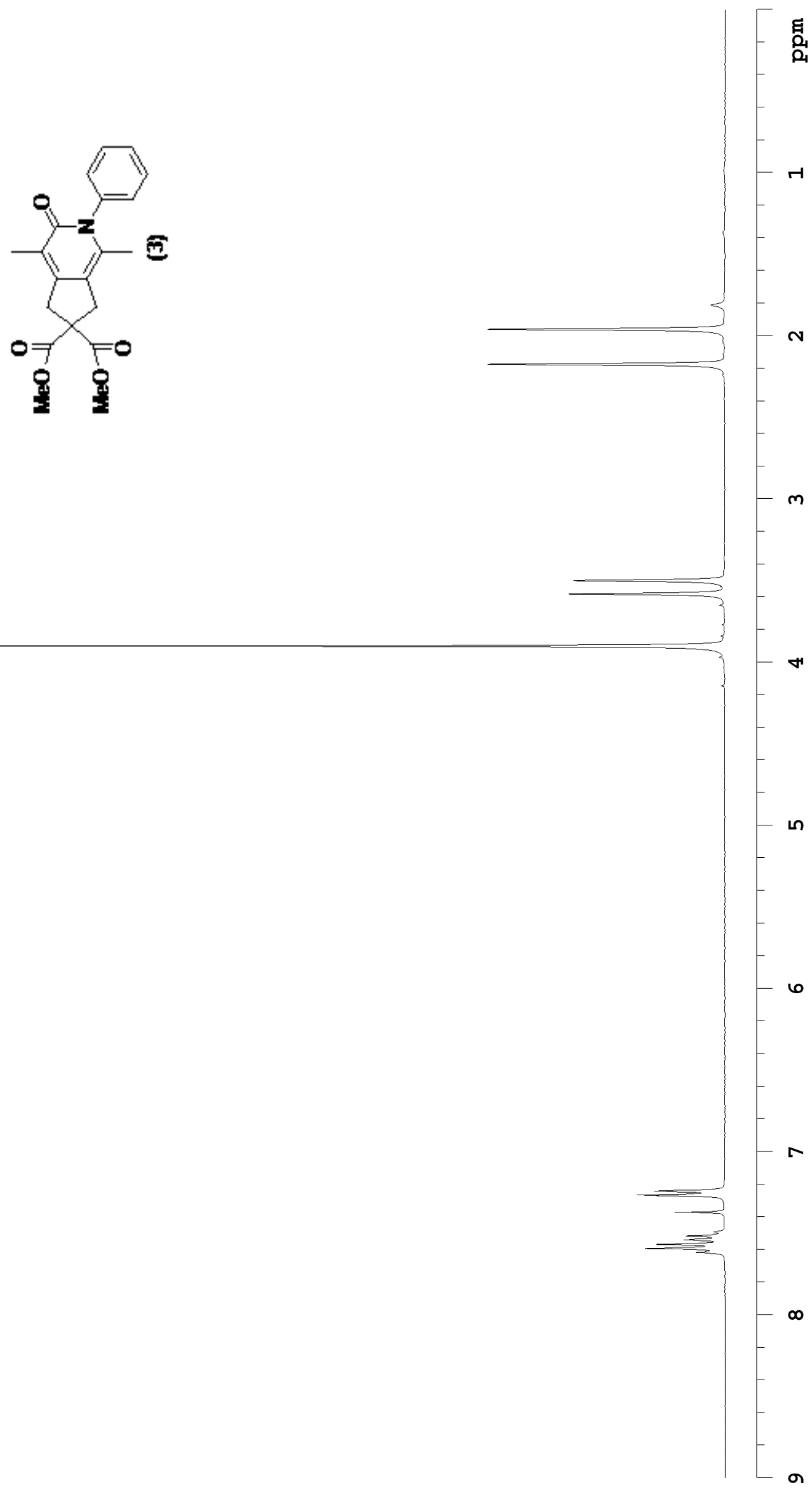

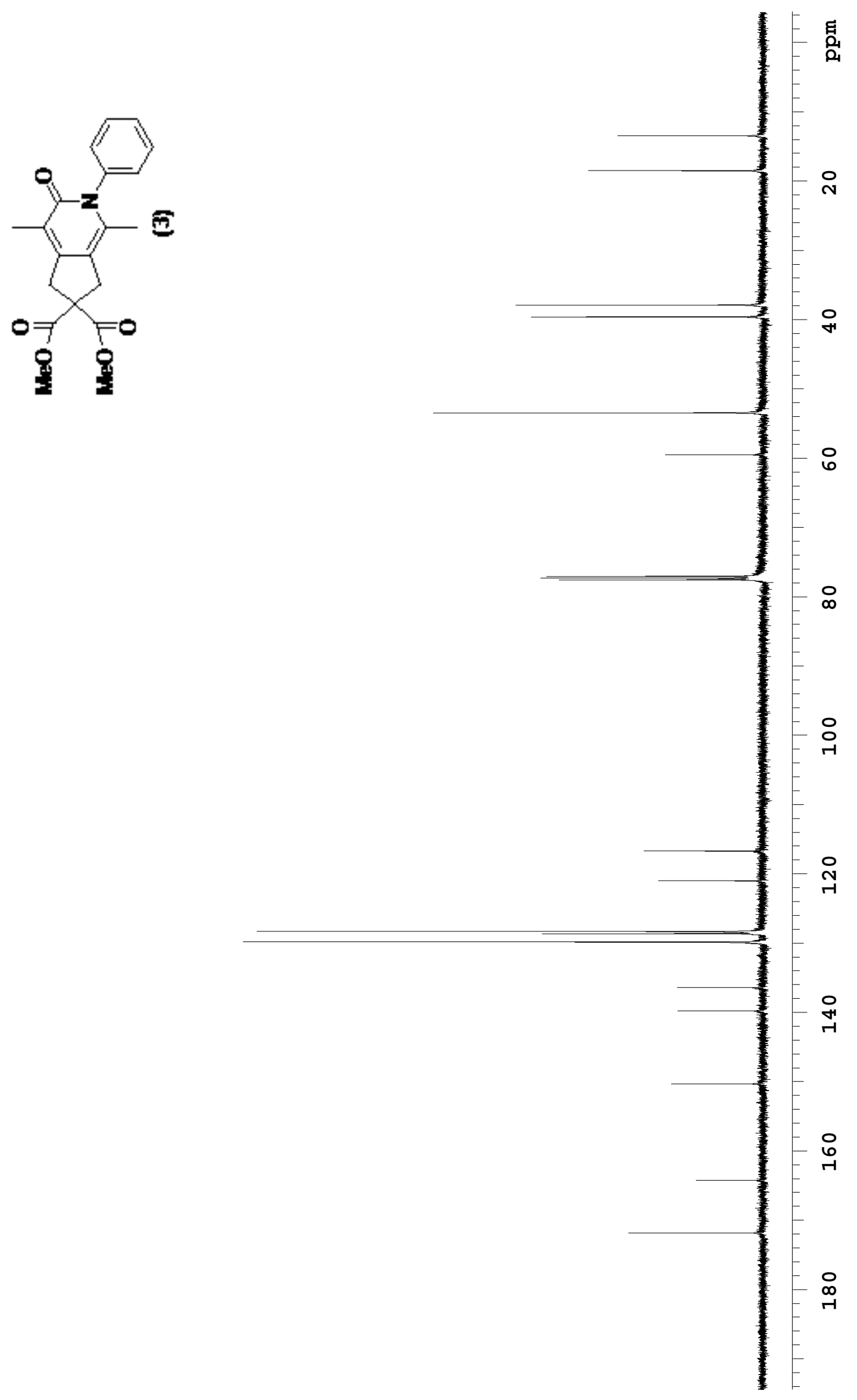

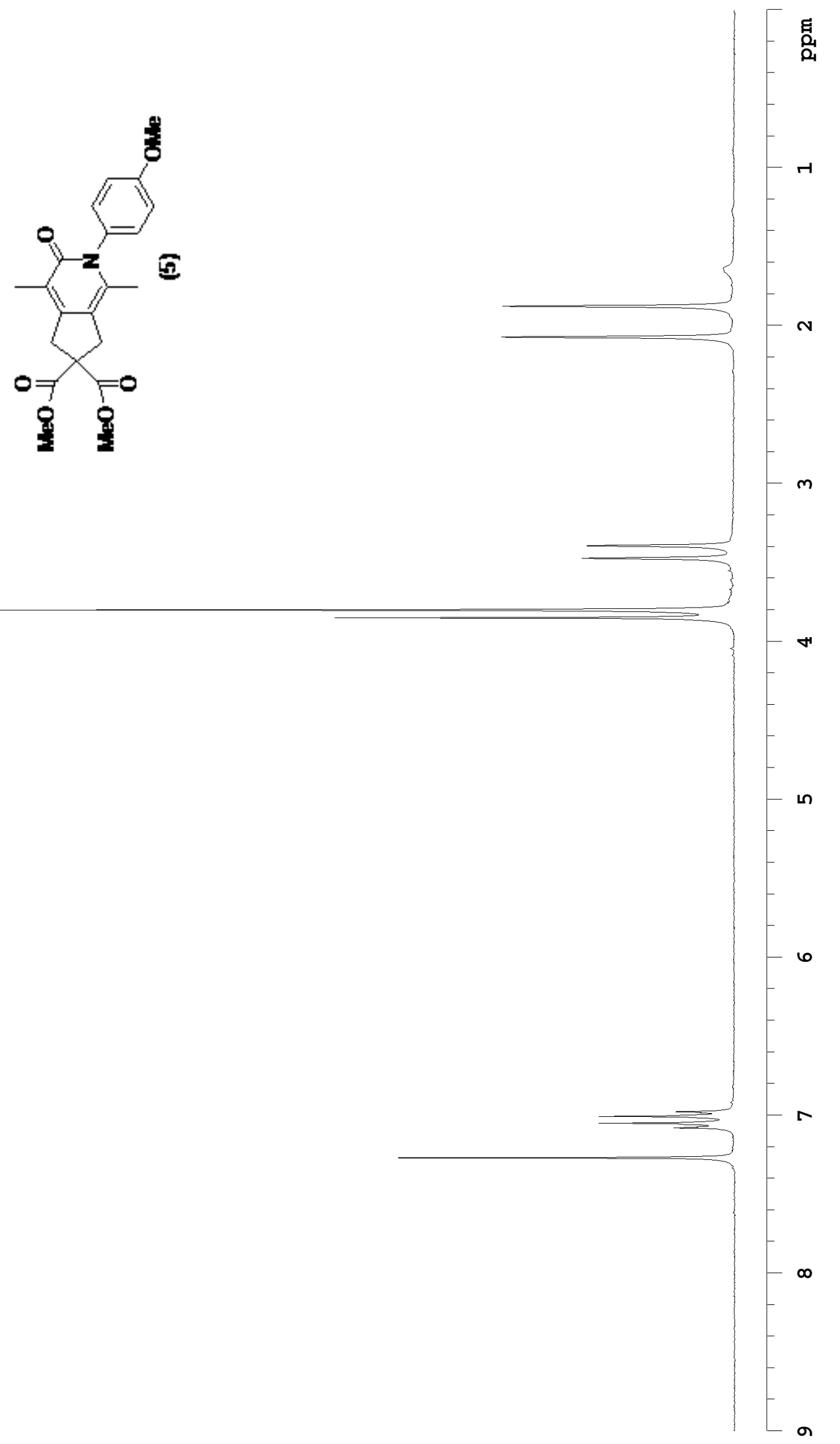

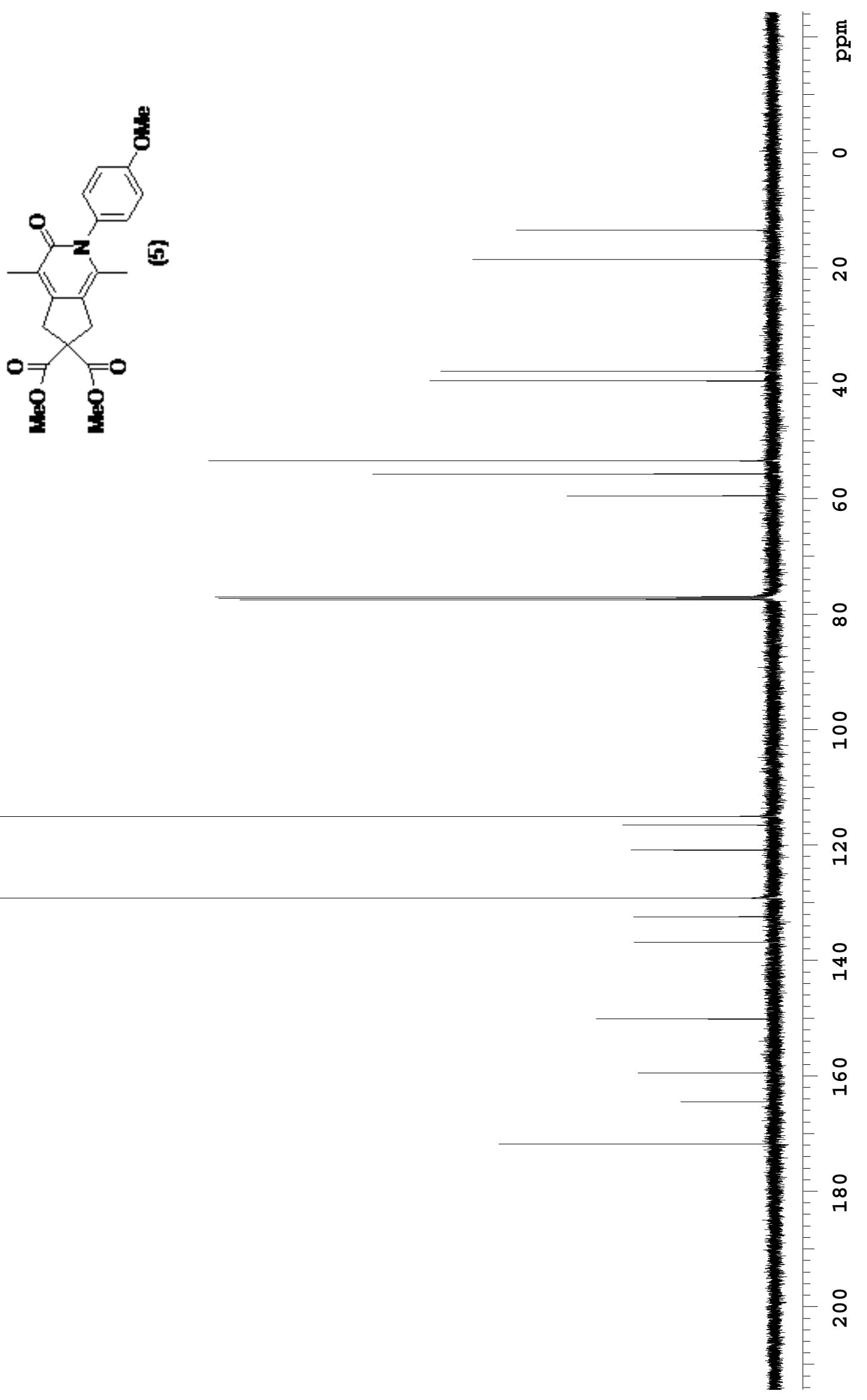

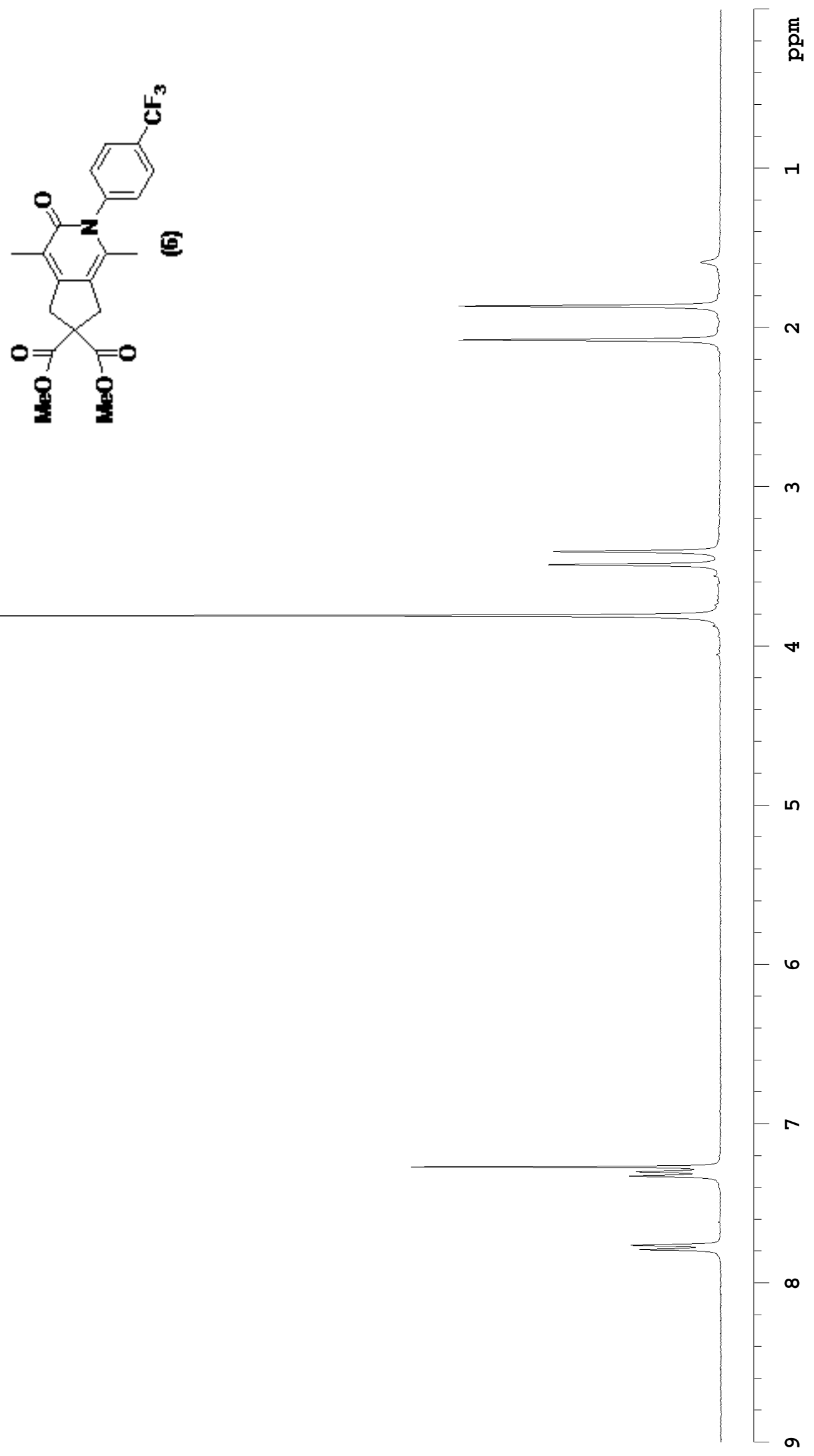

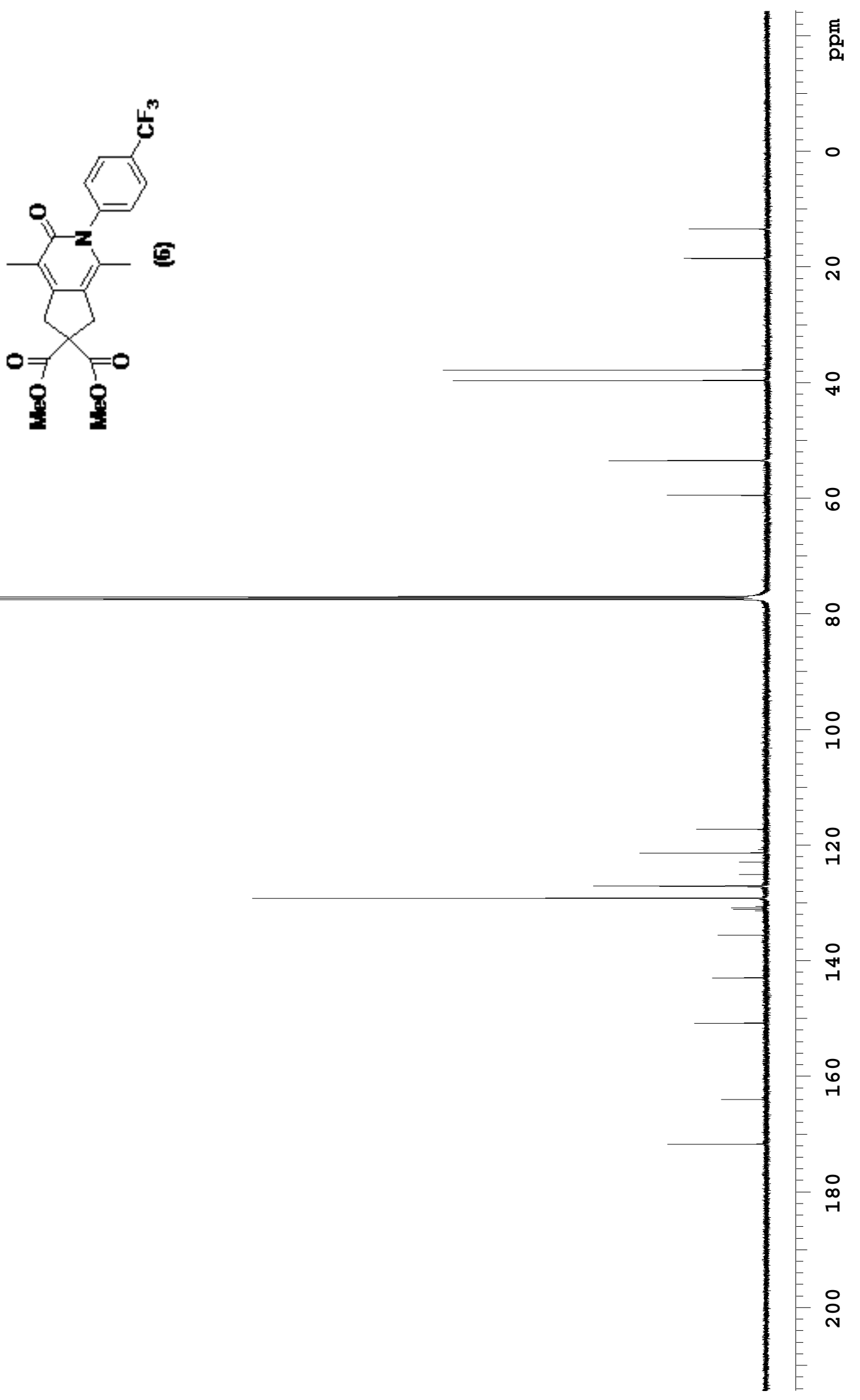

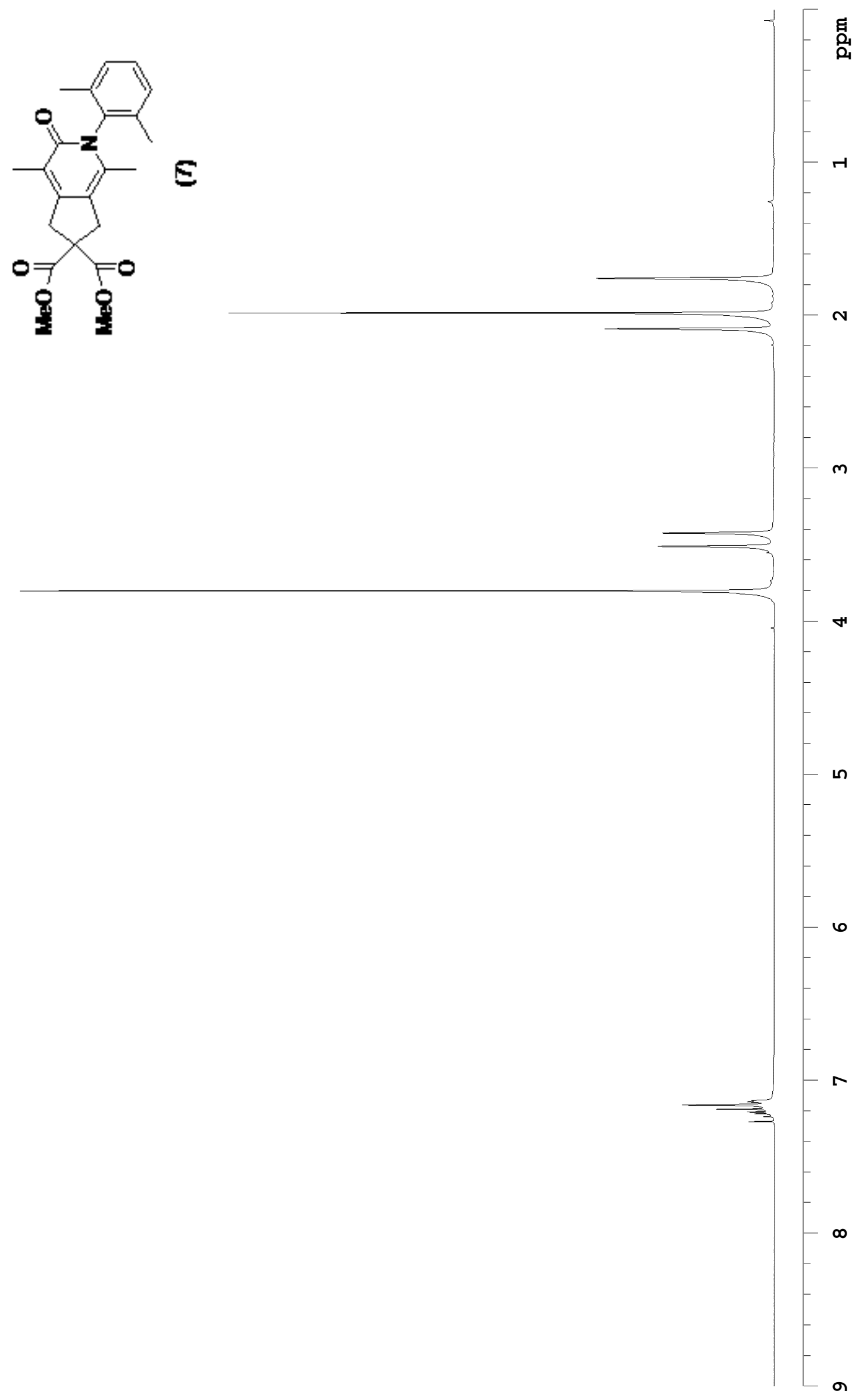

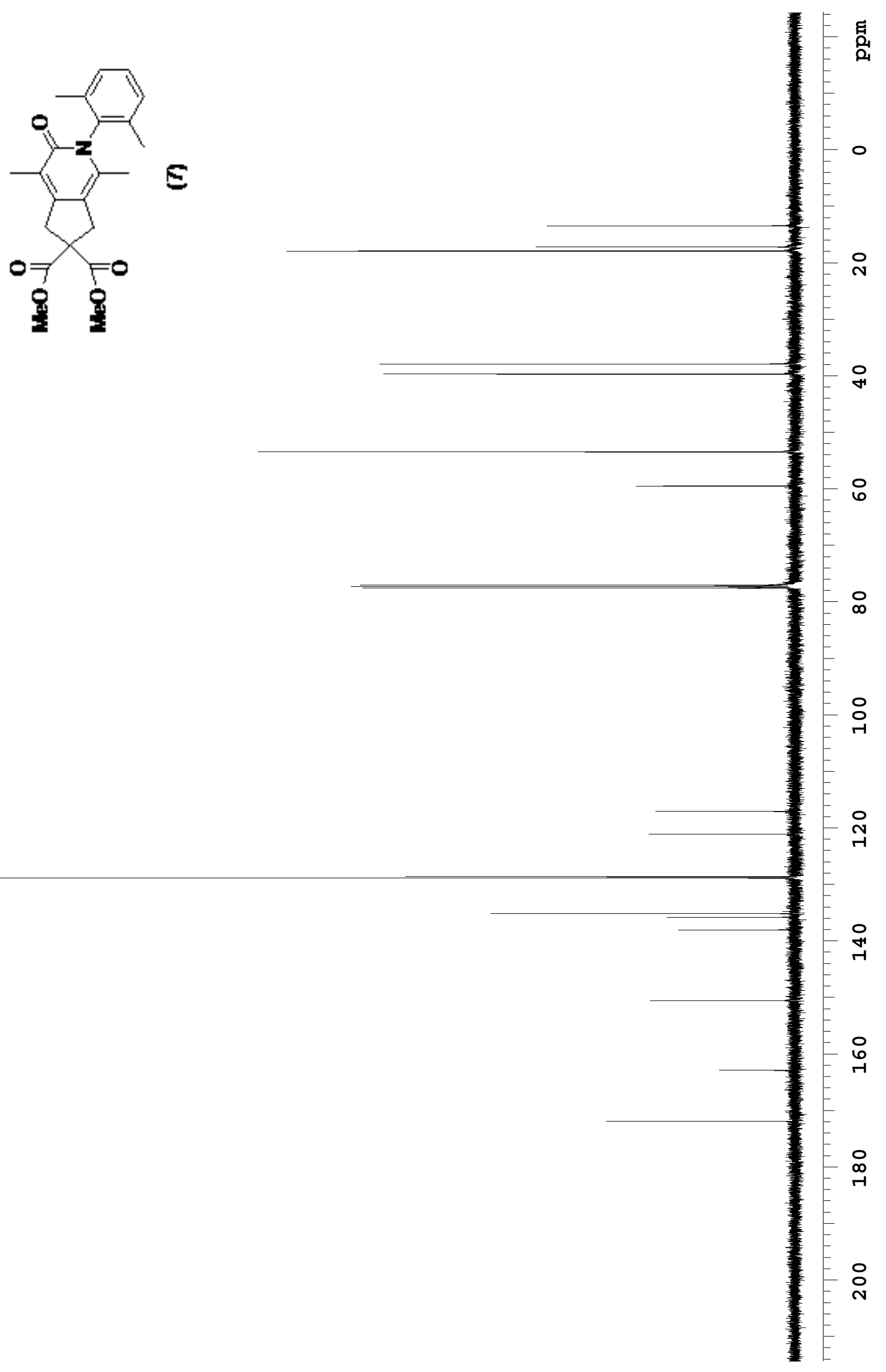

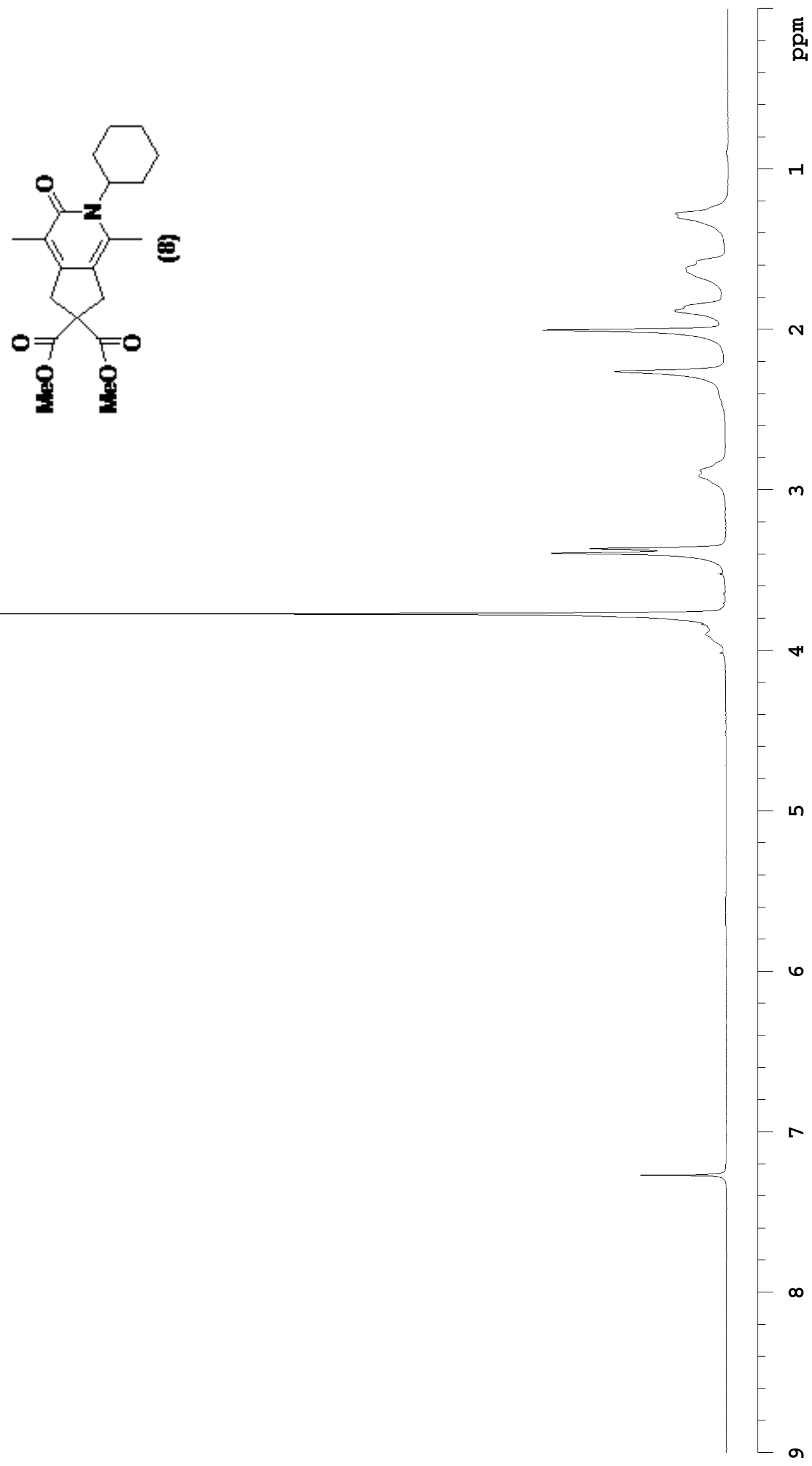

S14 


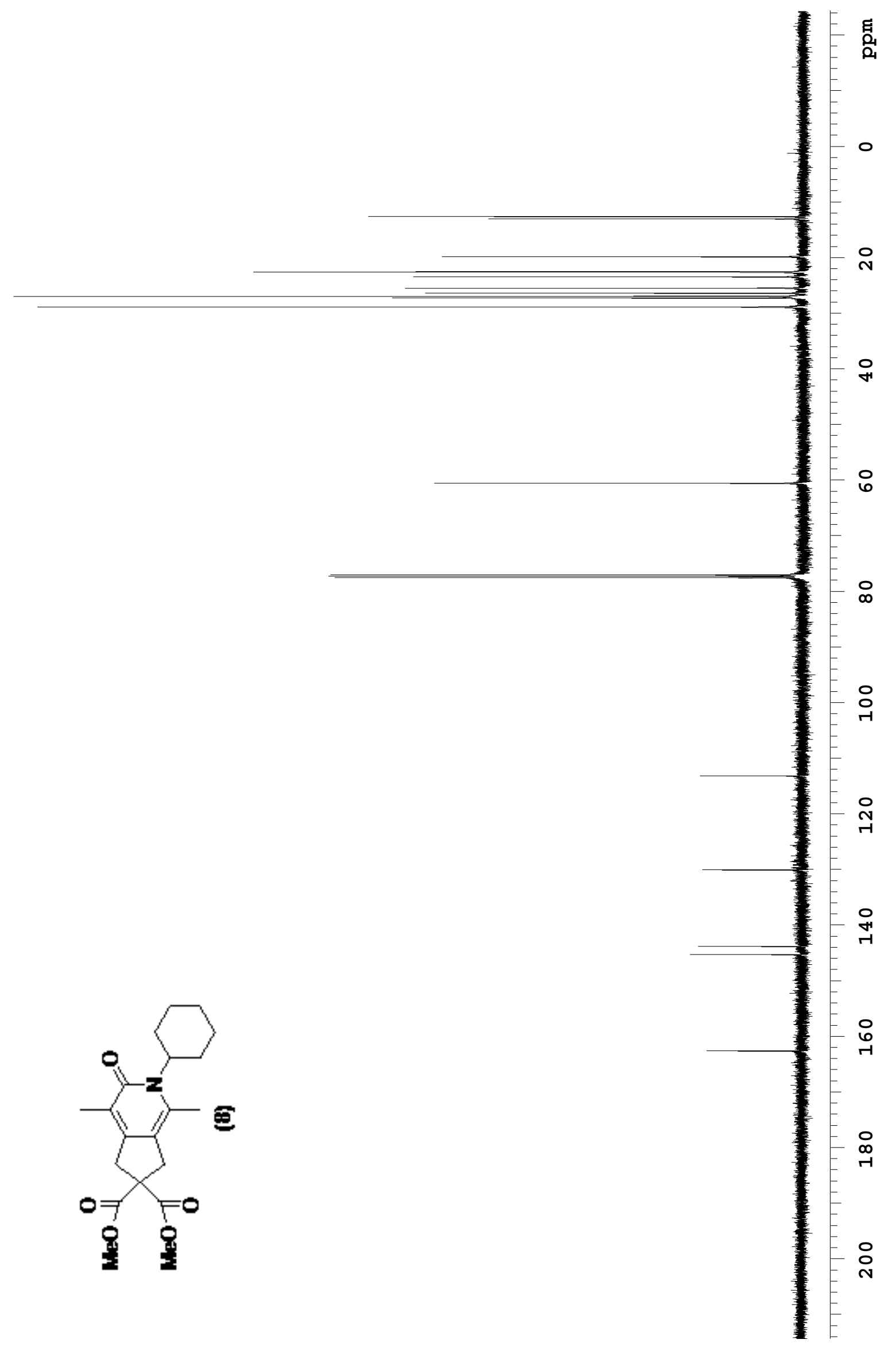



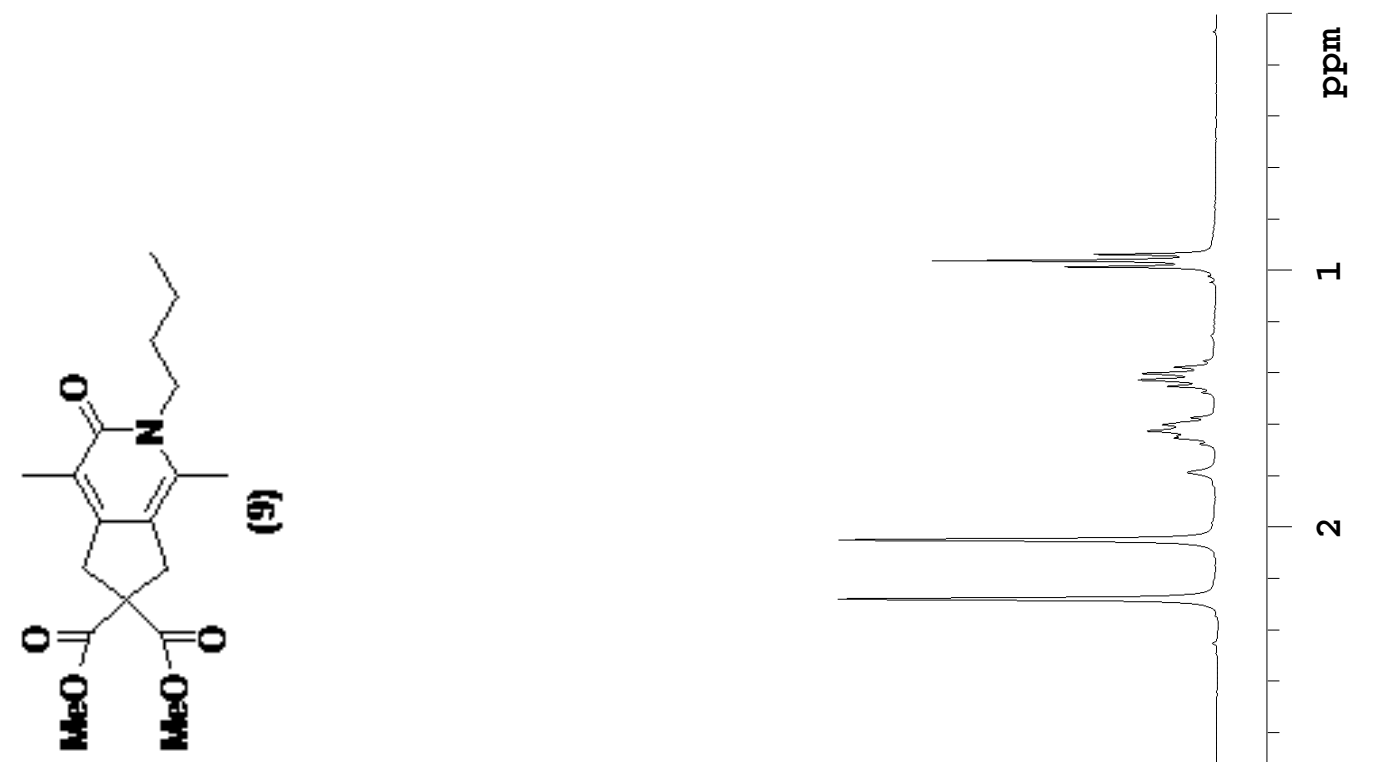

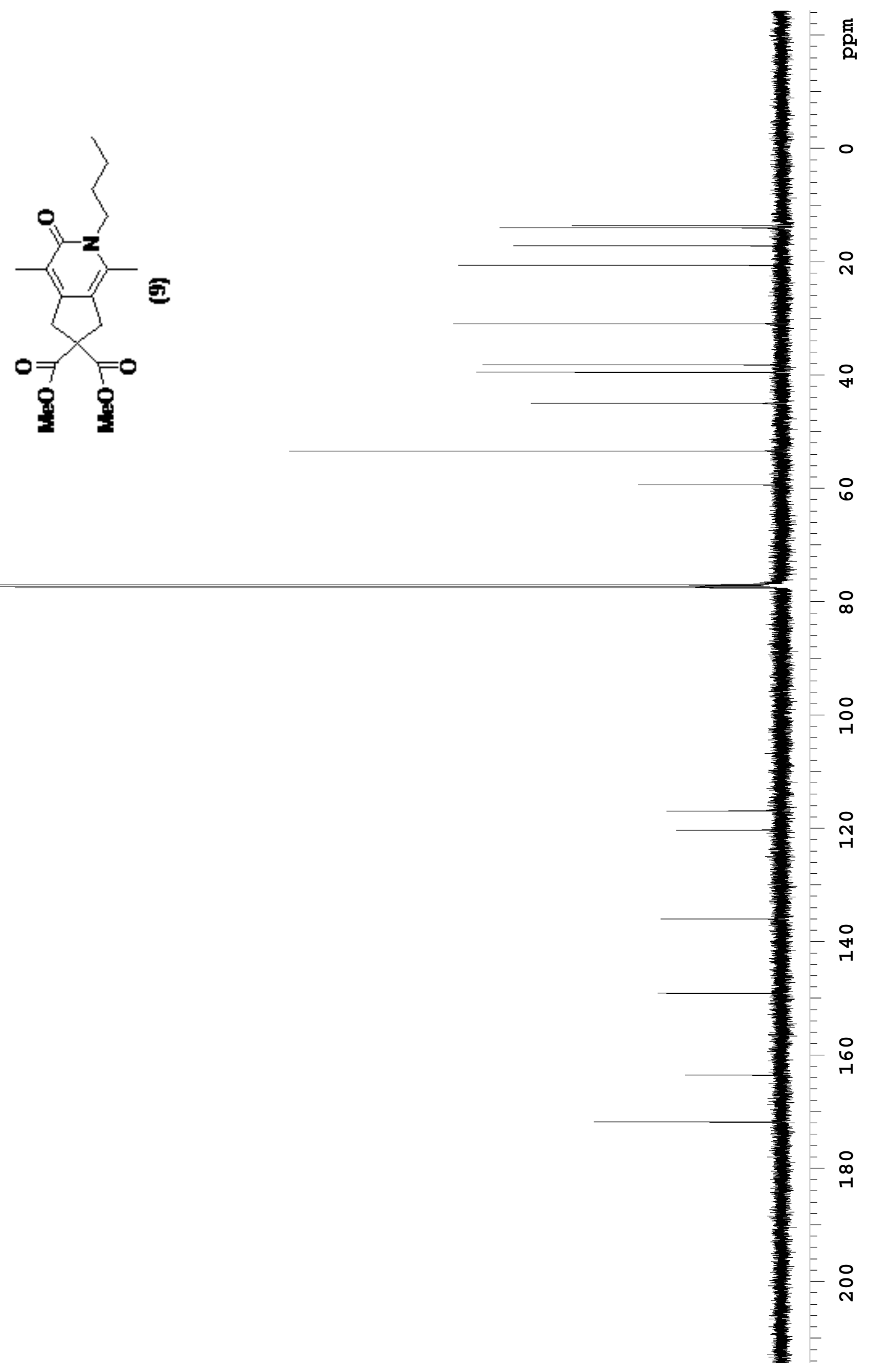

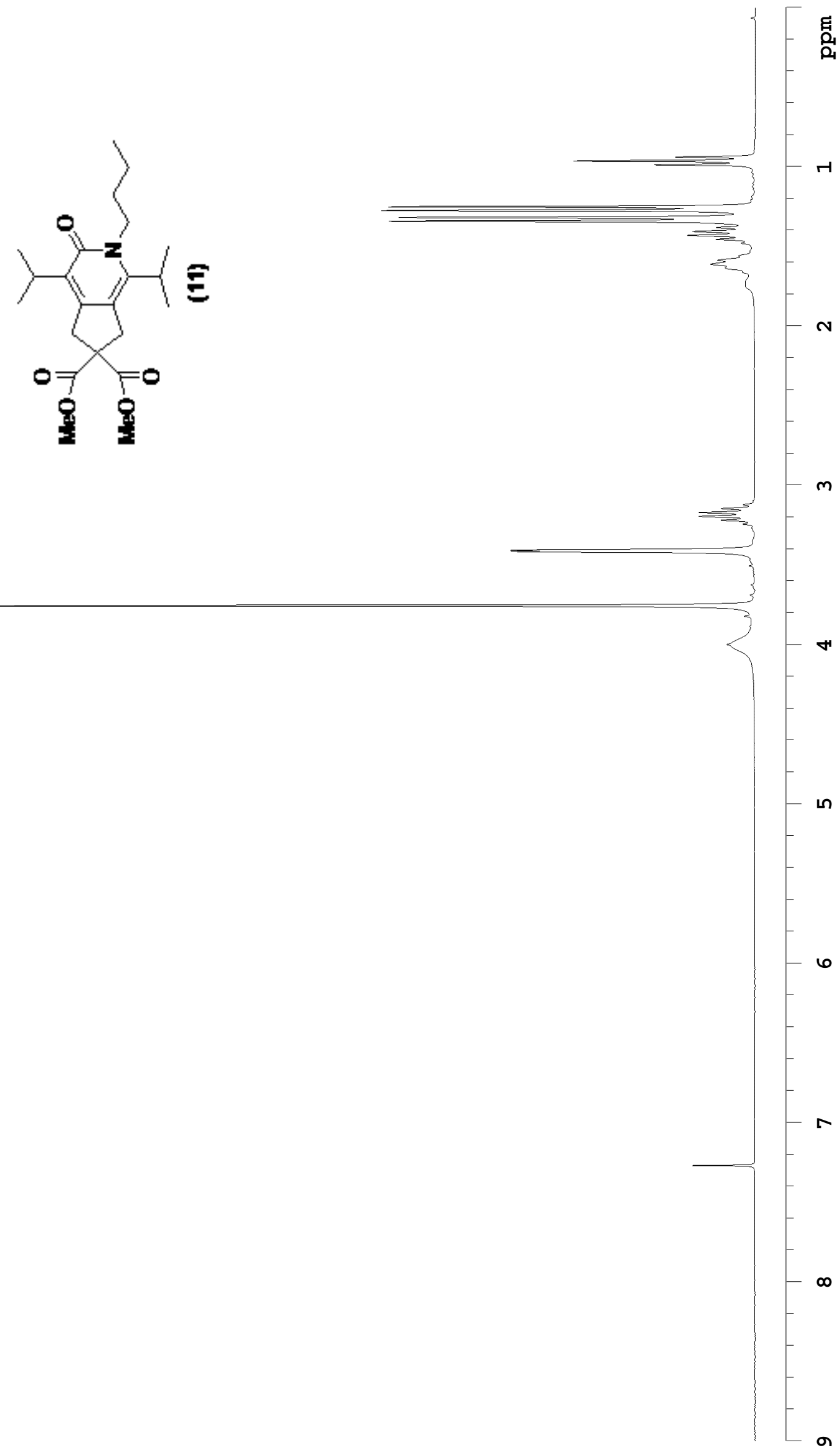


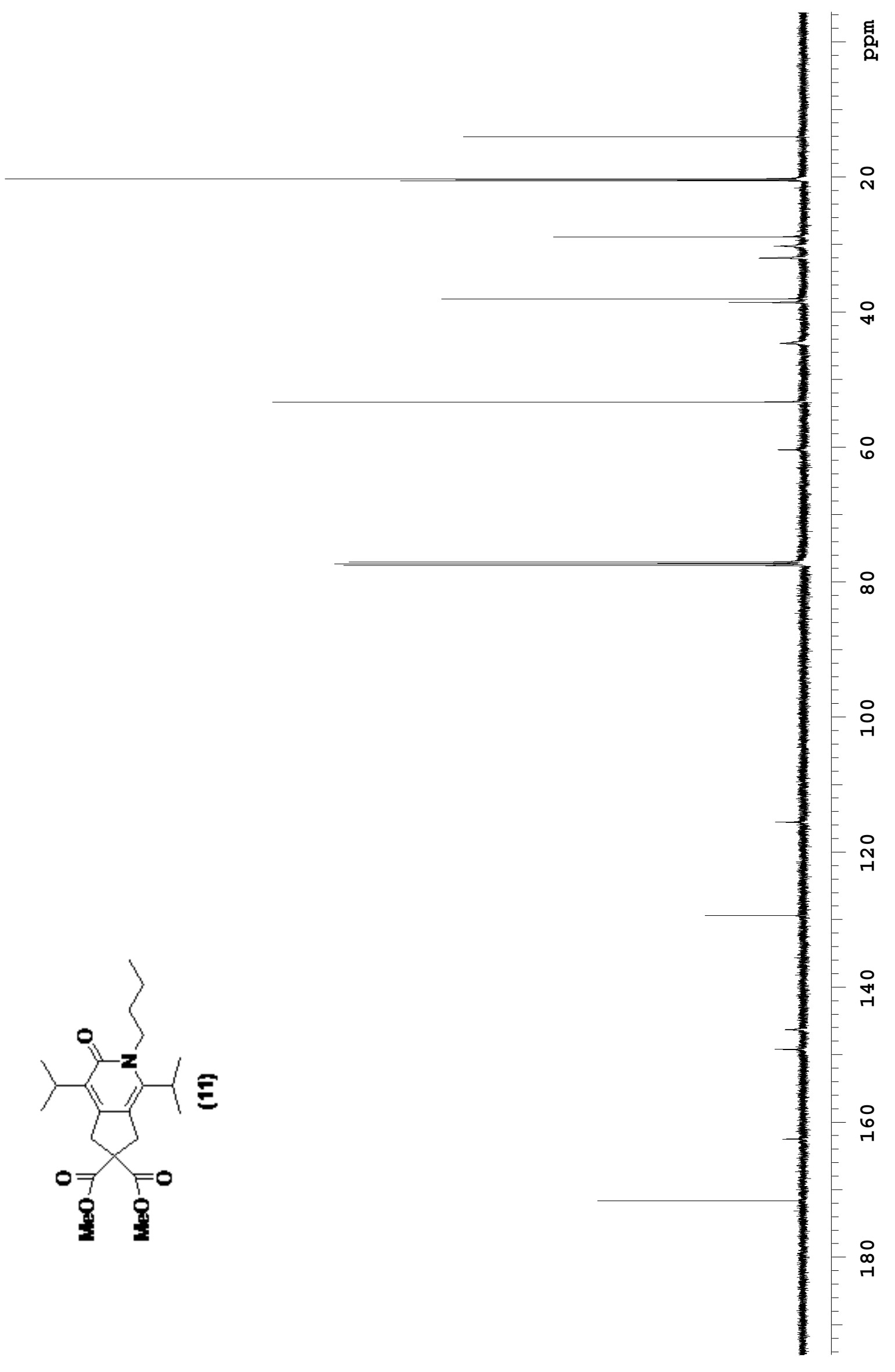




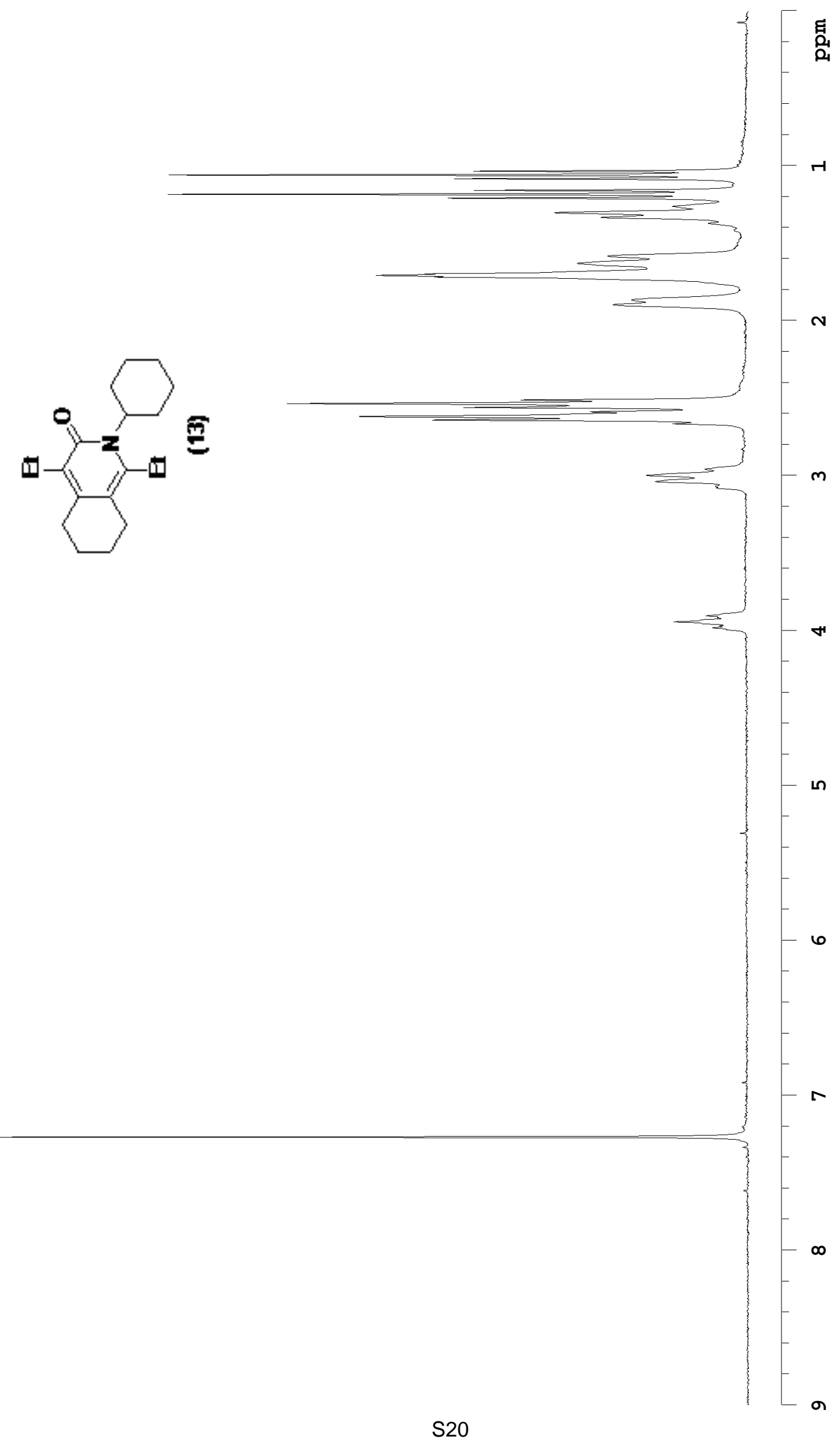




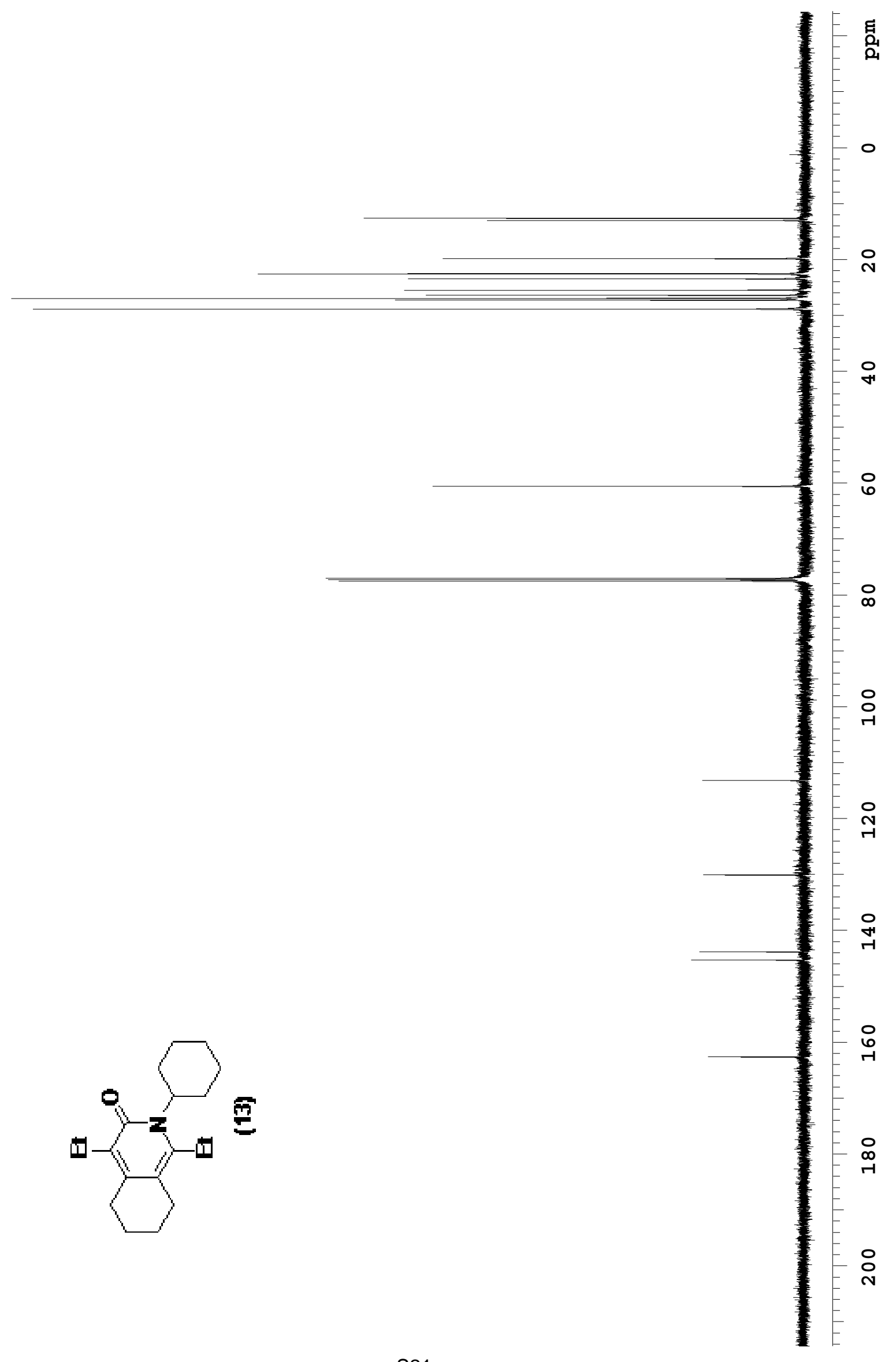




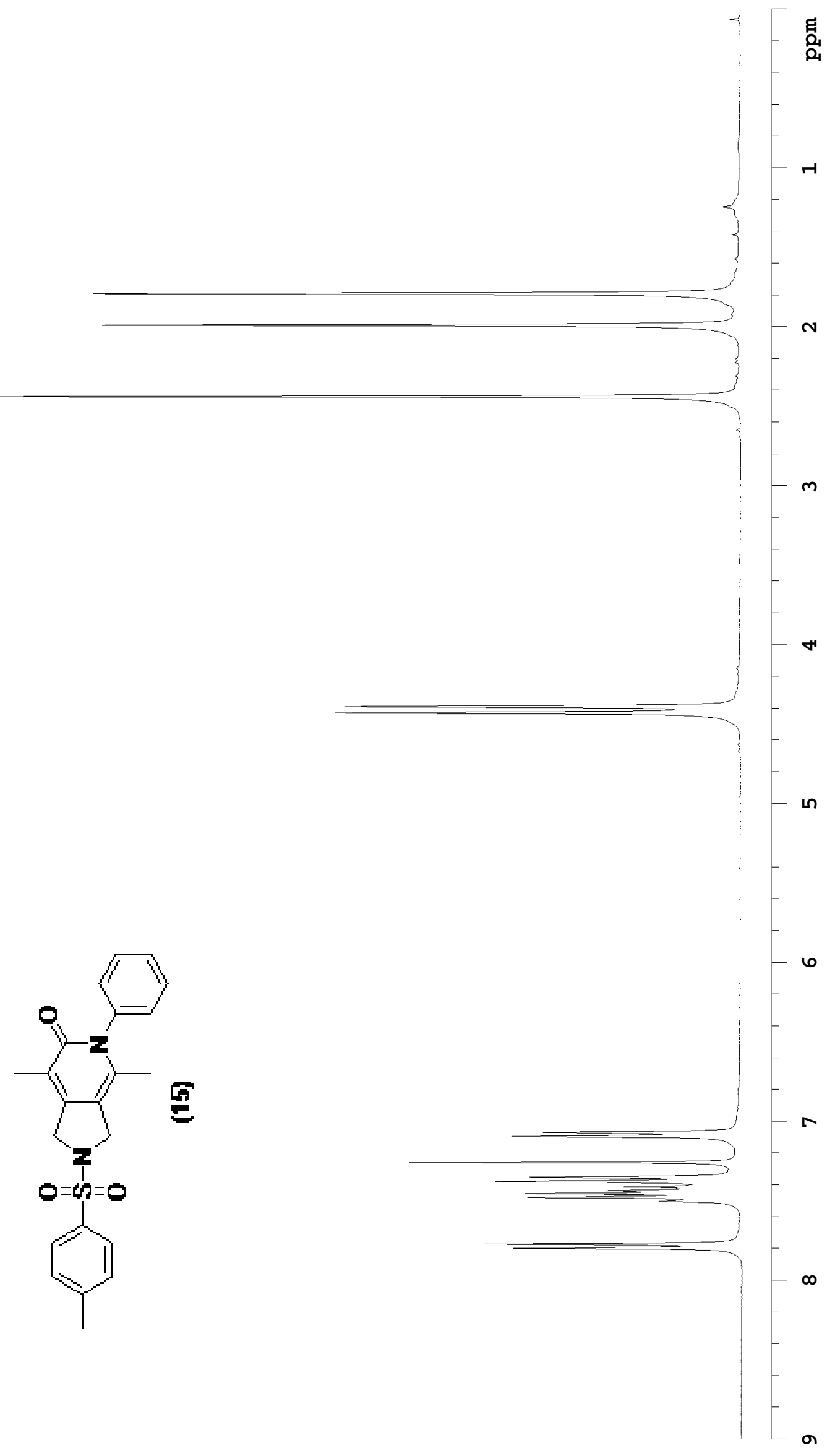




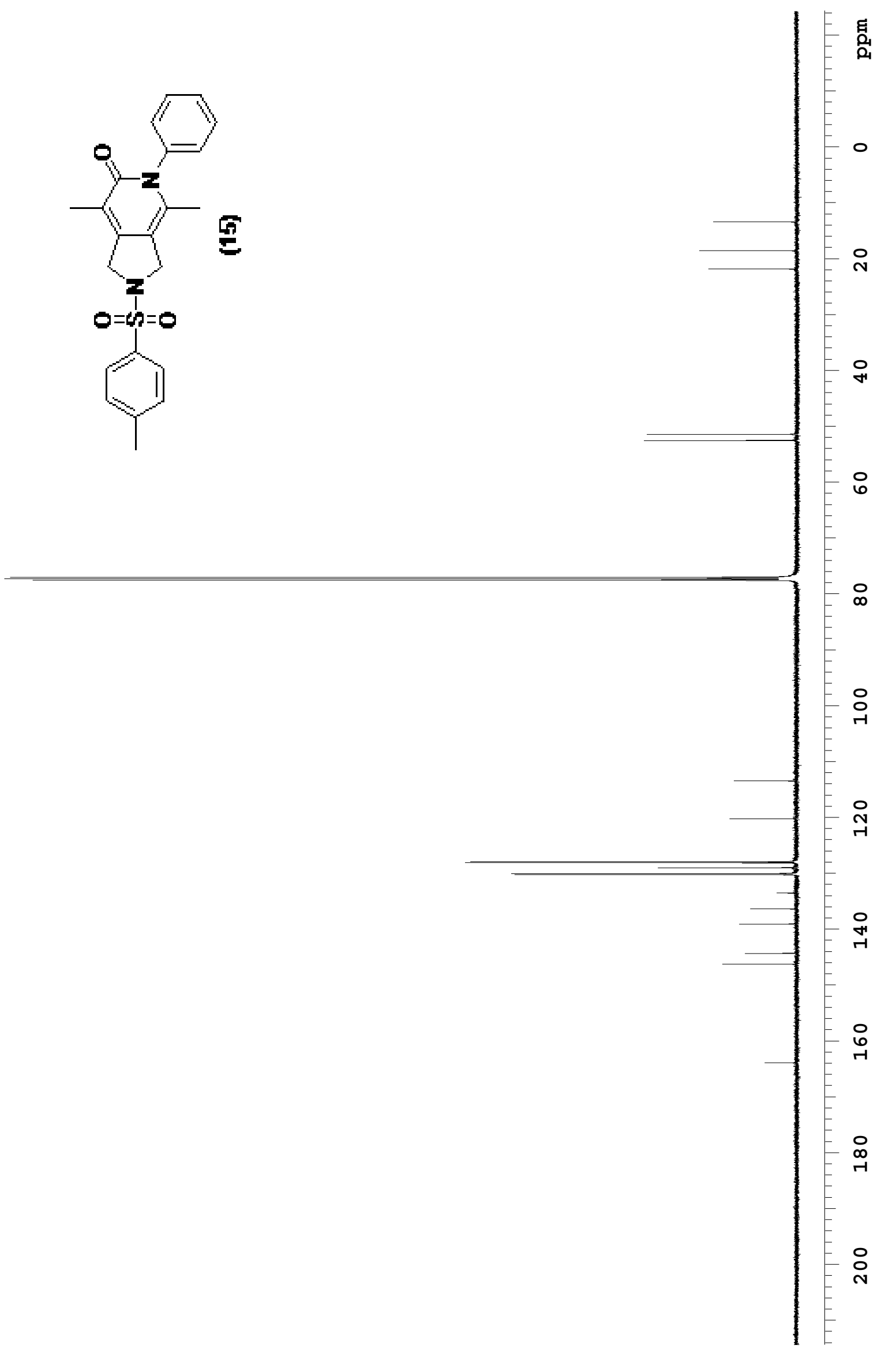




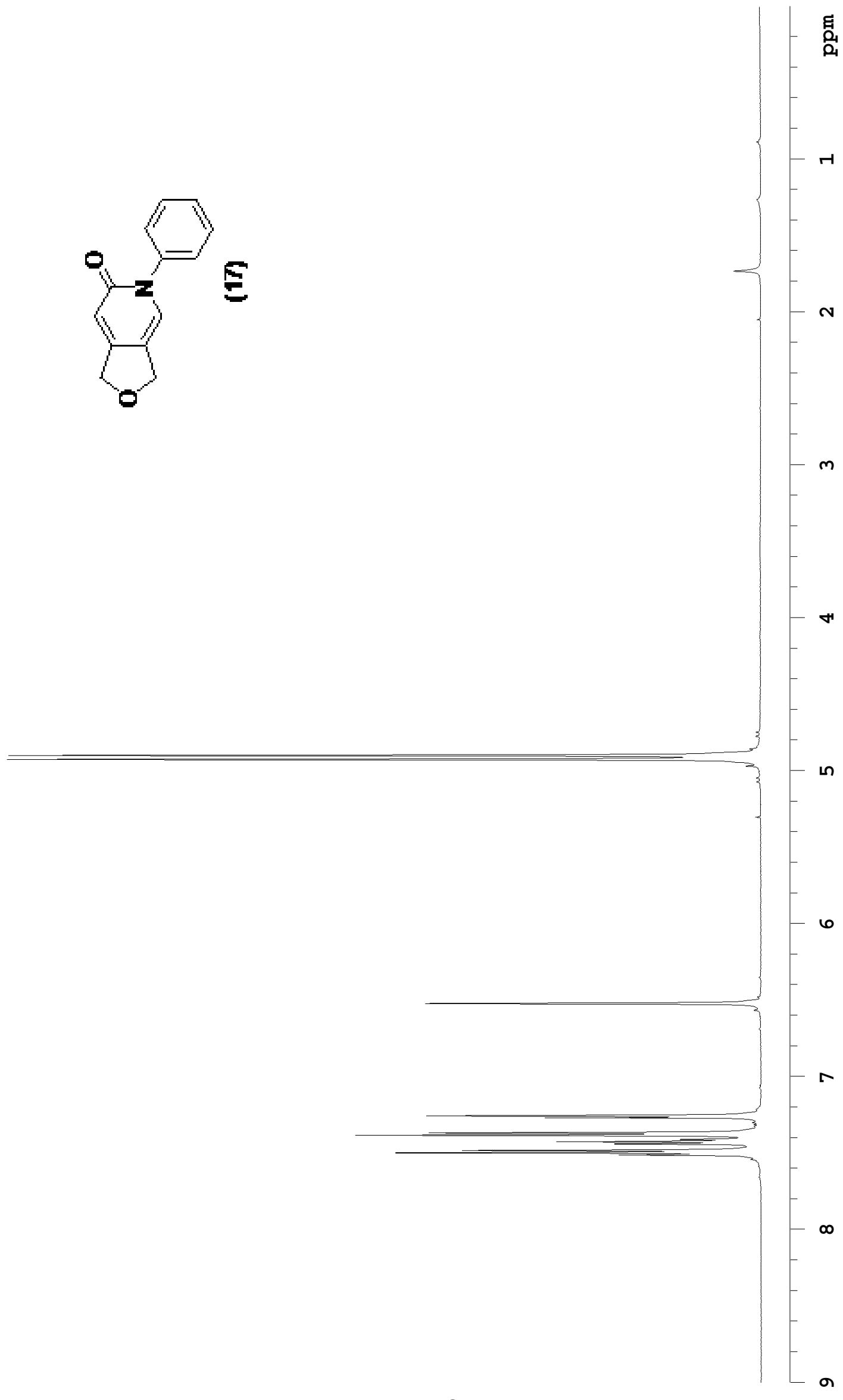




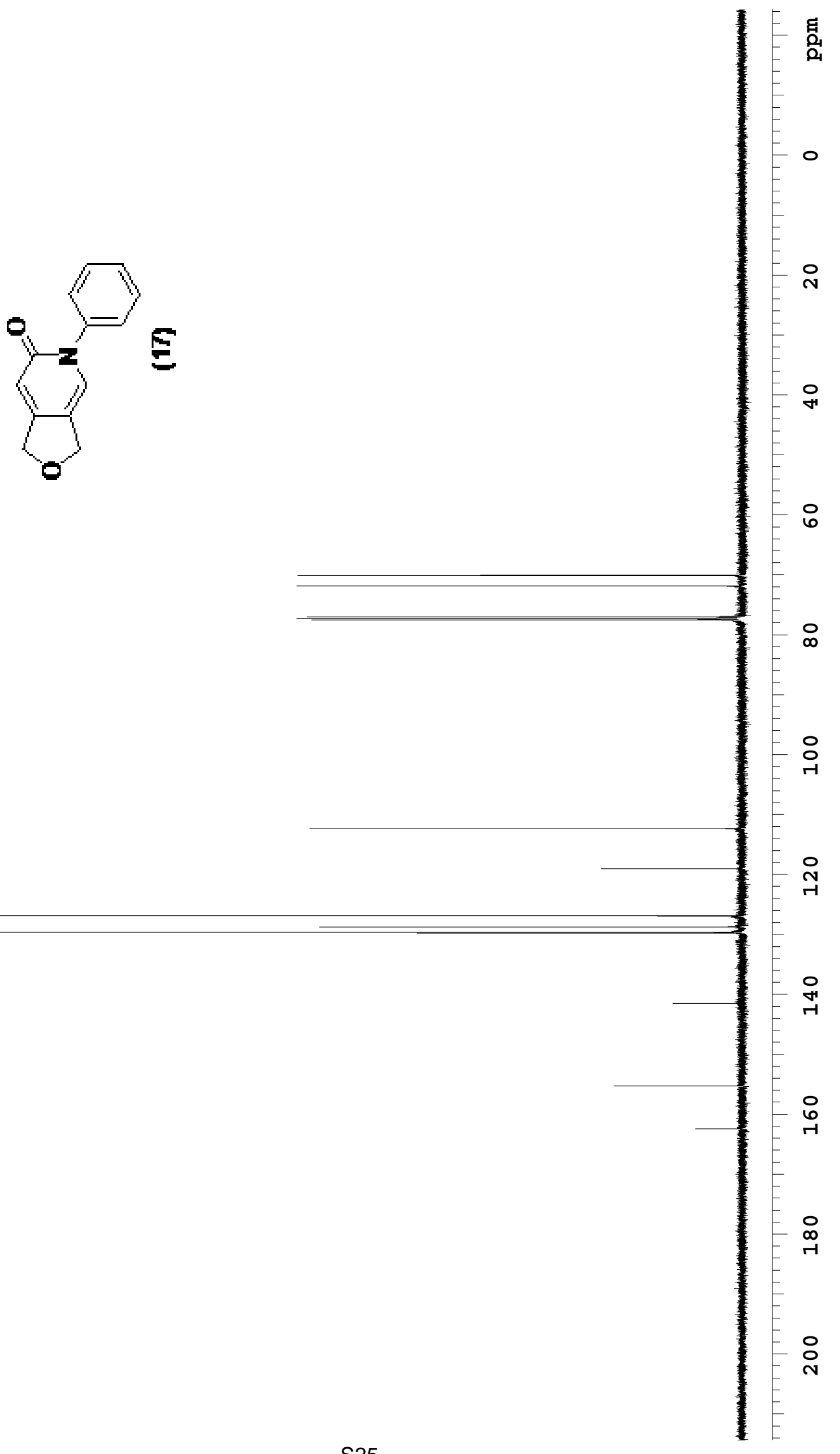



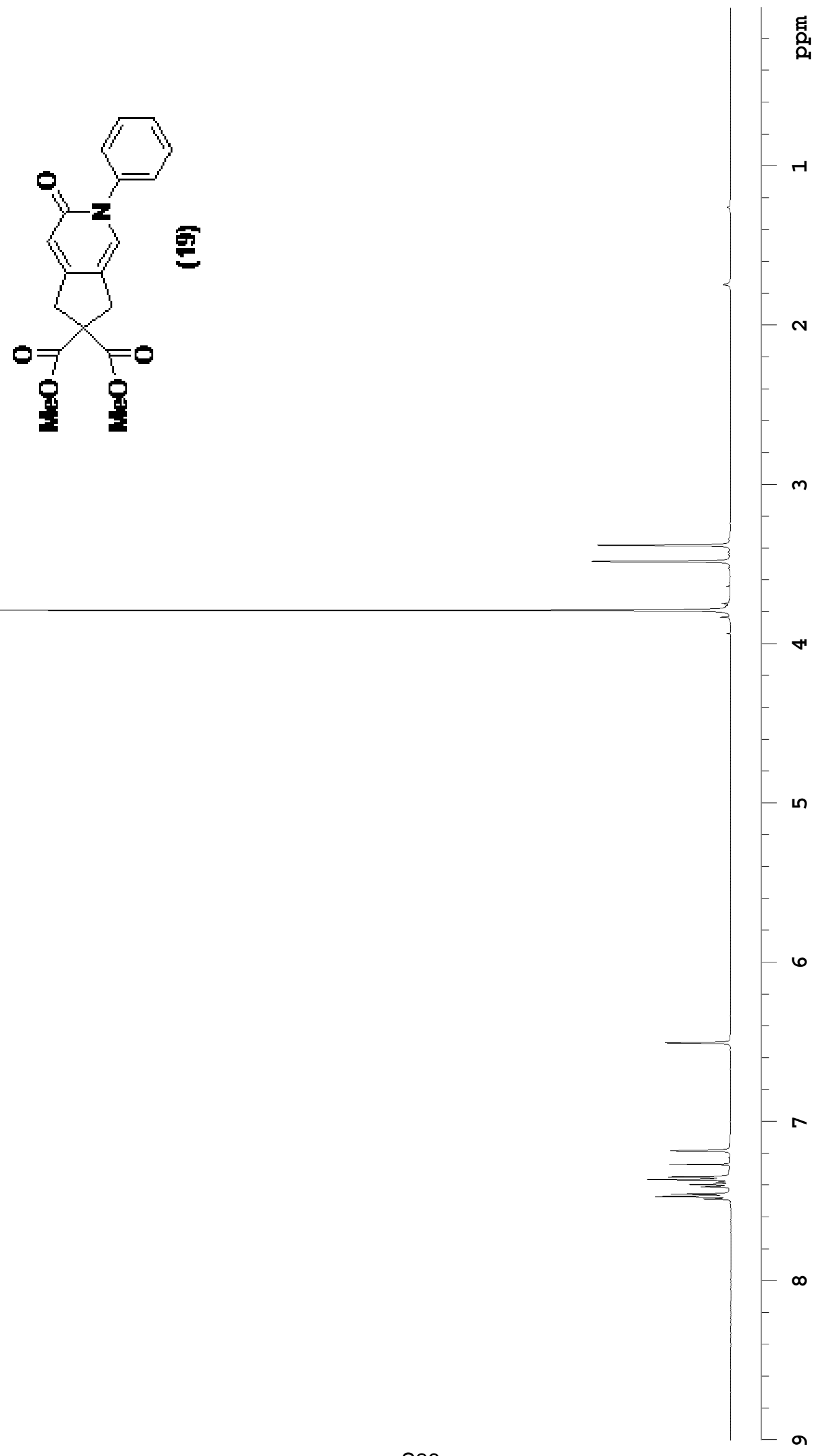

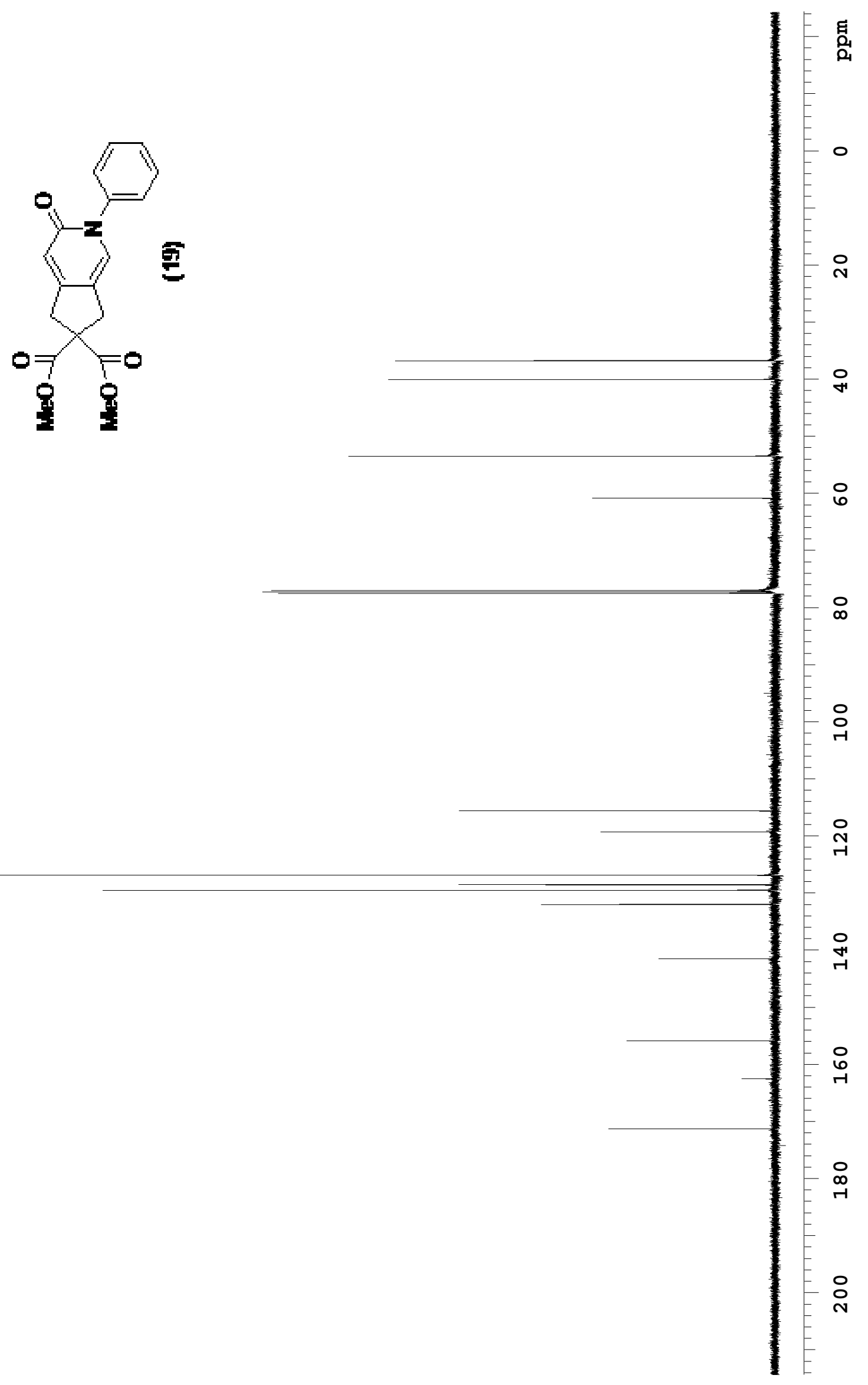

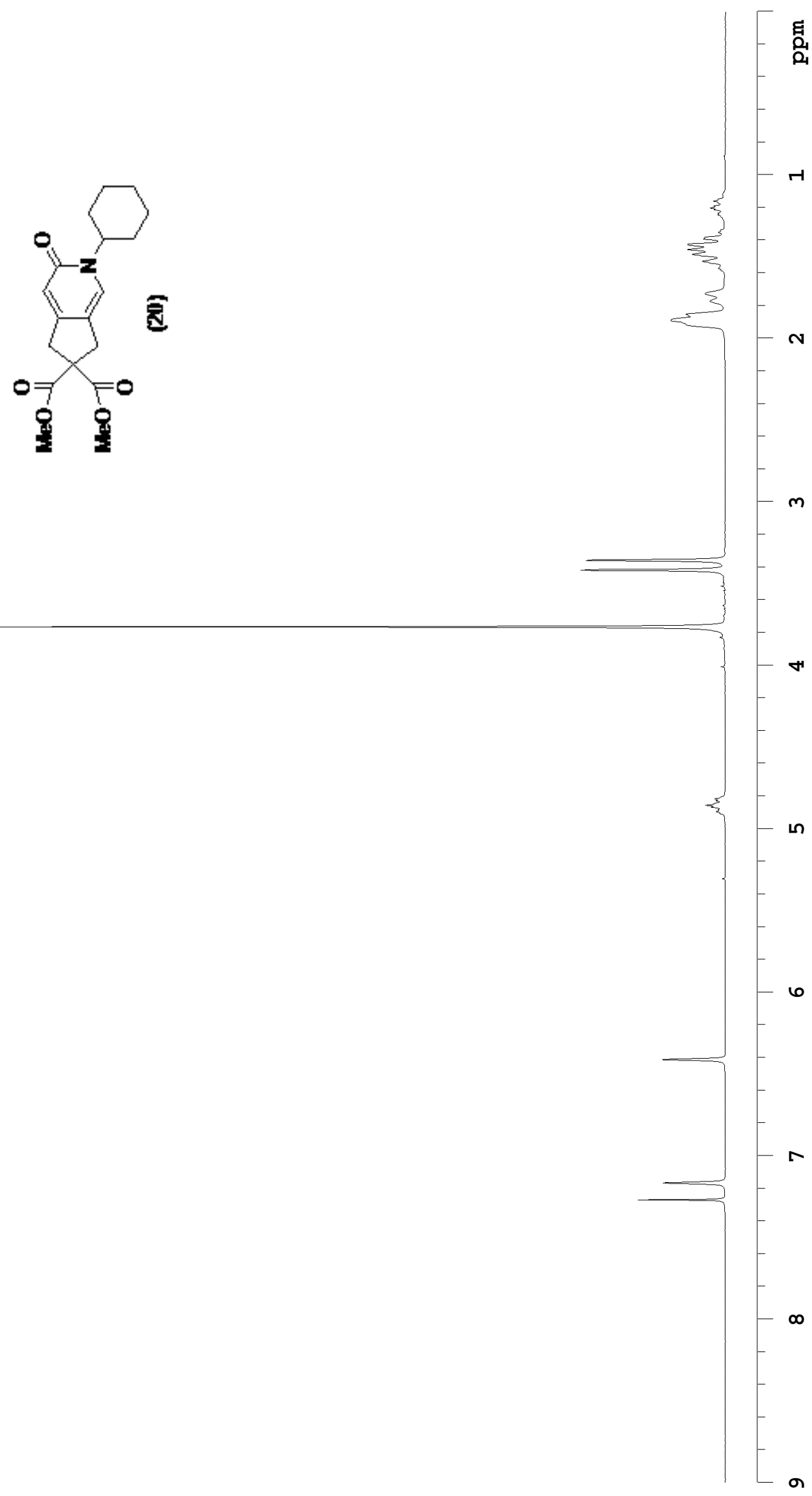


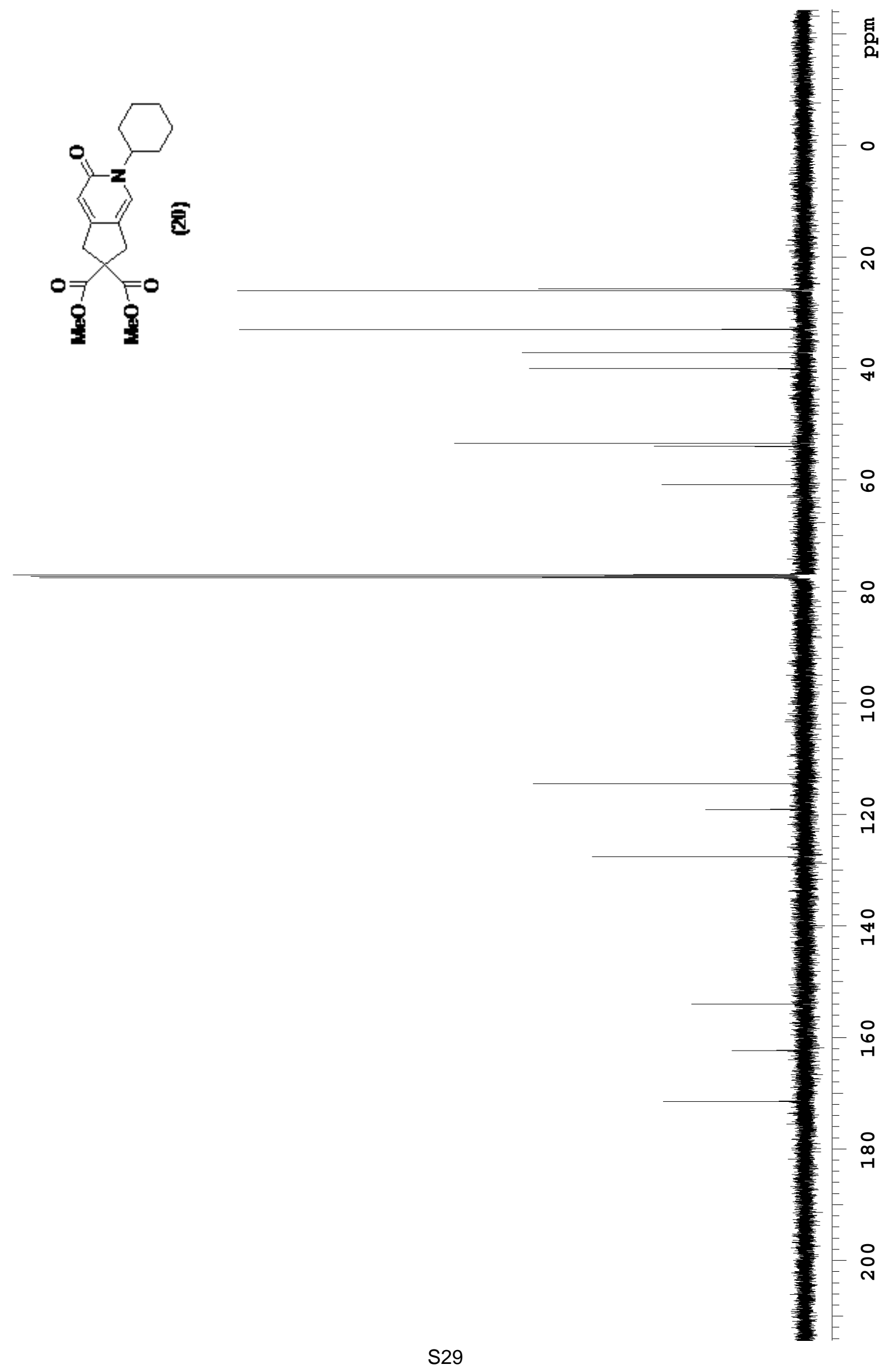



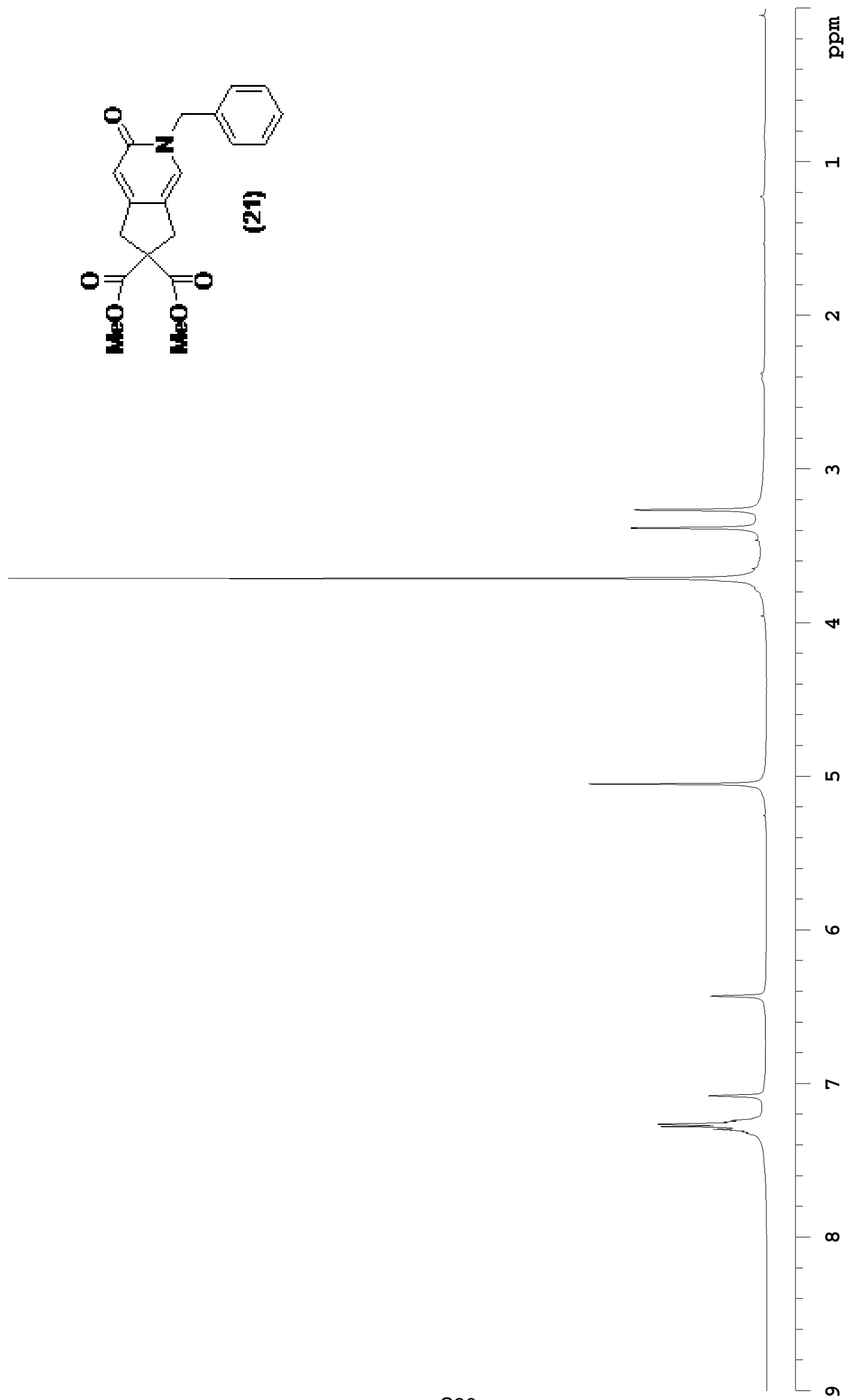

S30 

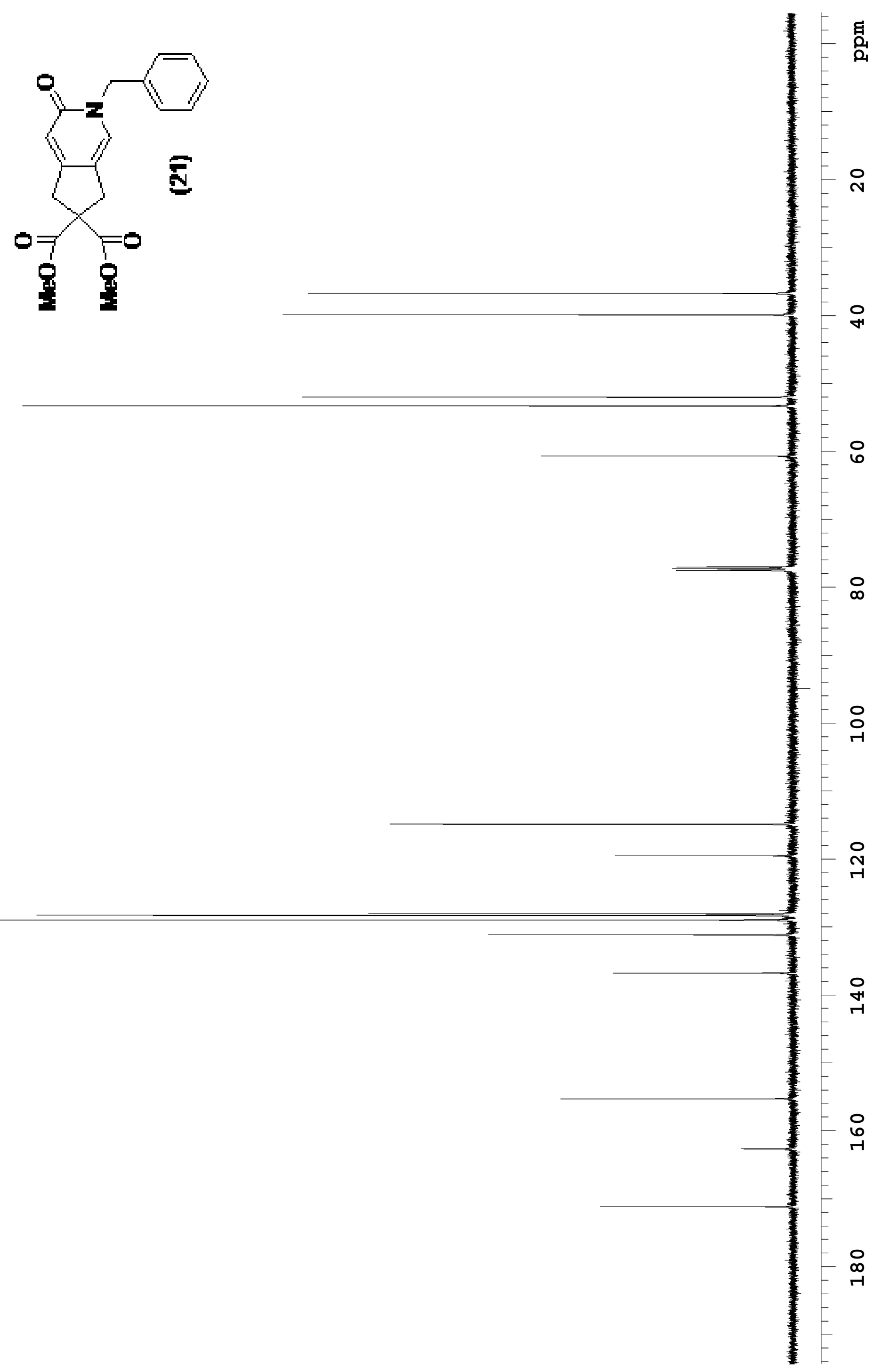


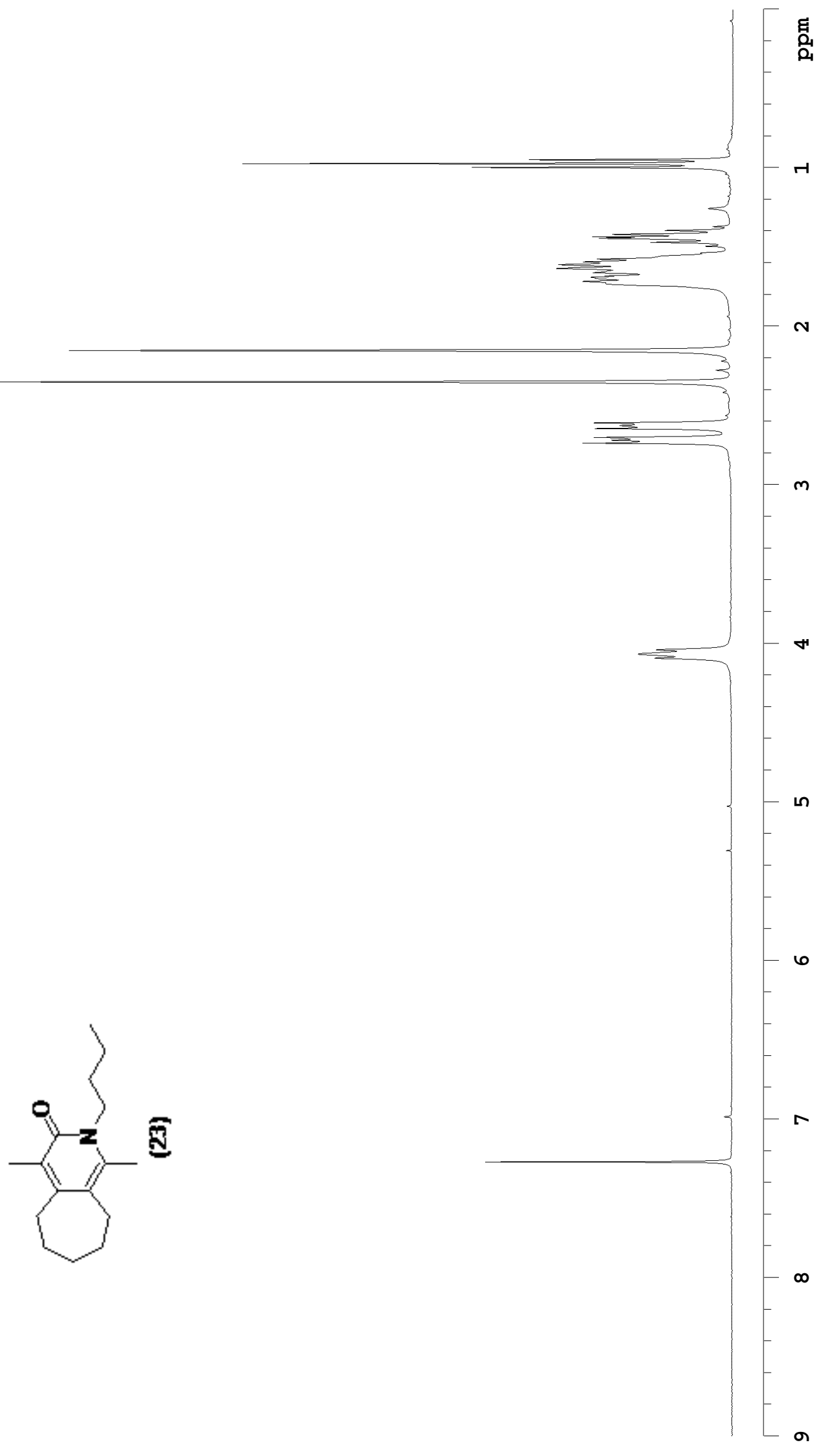




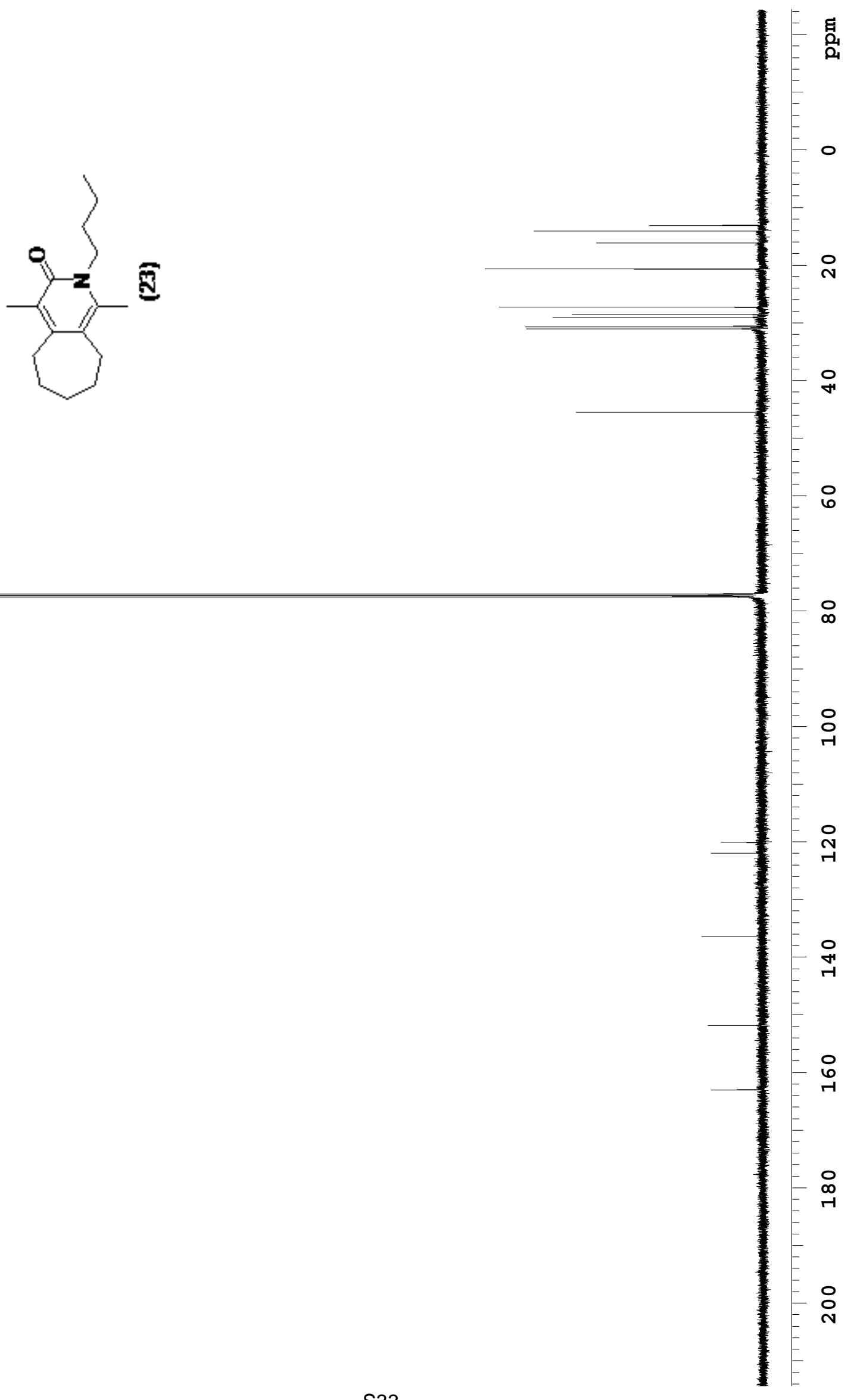




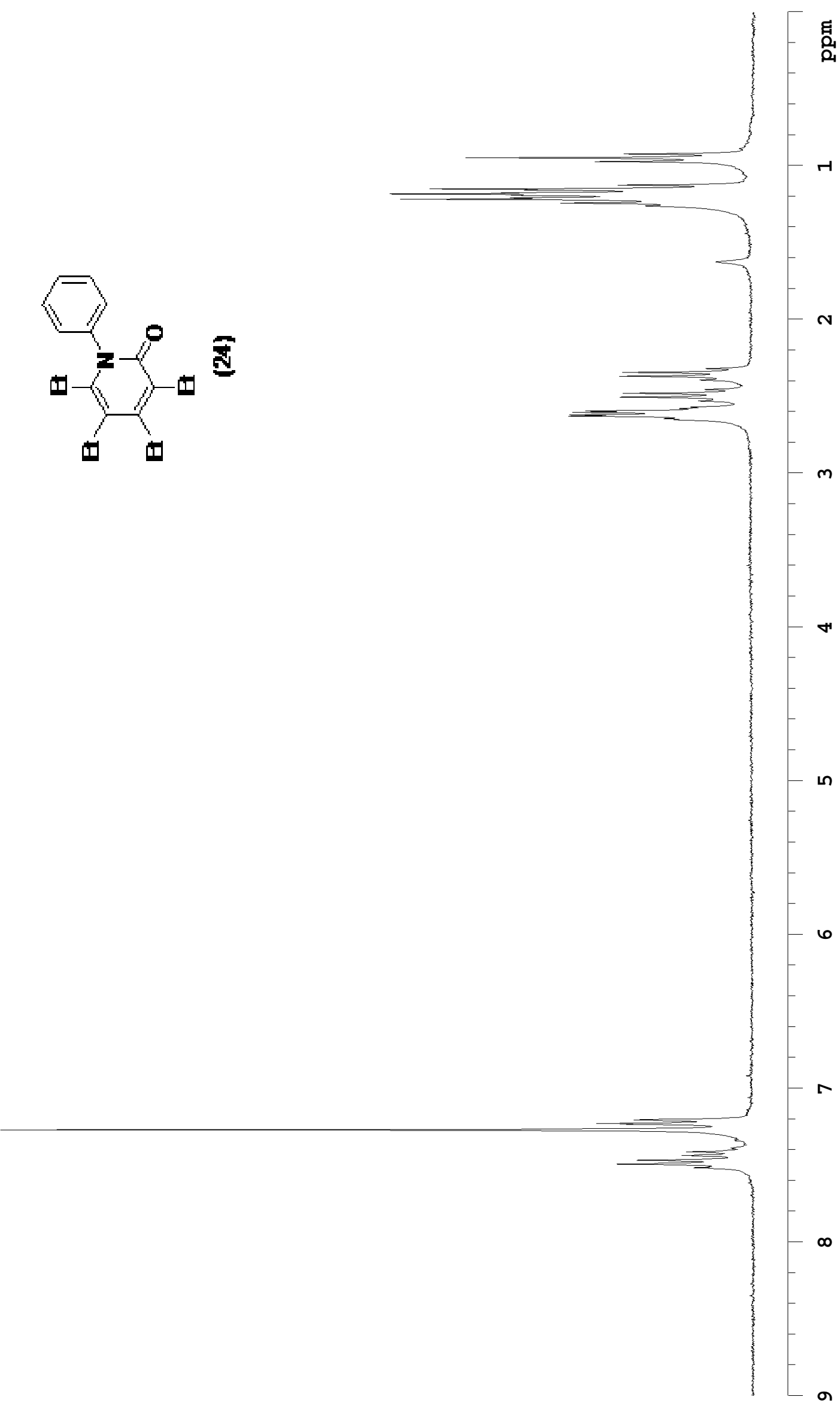



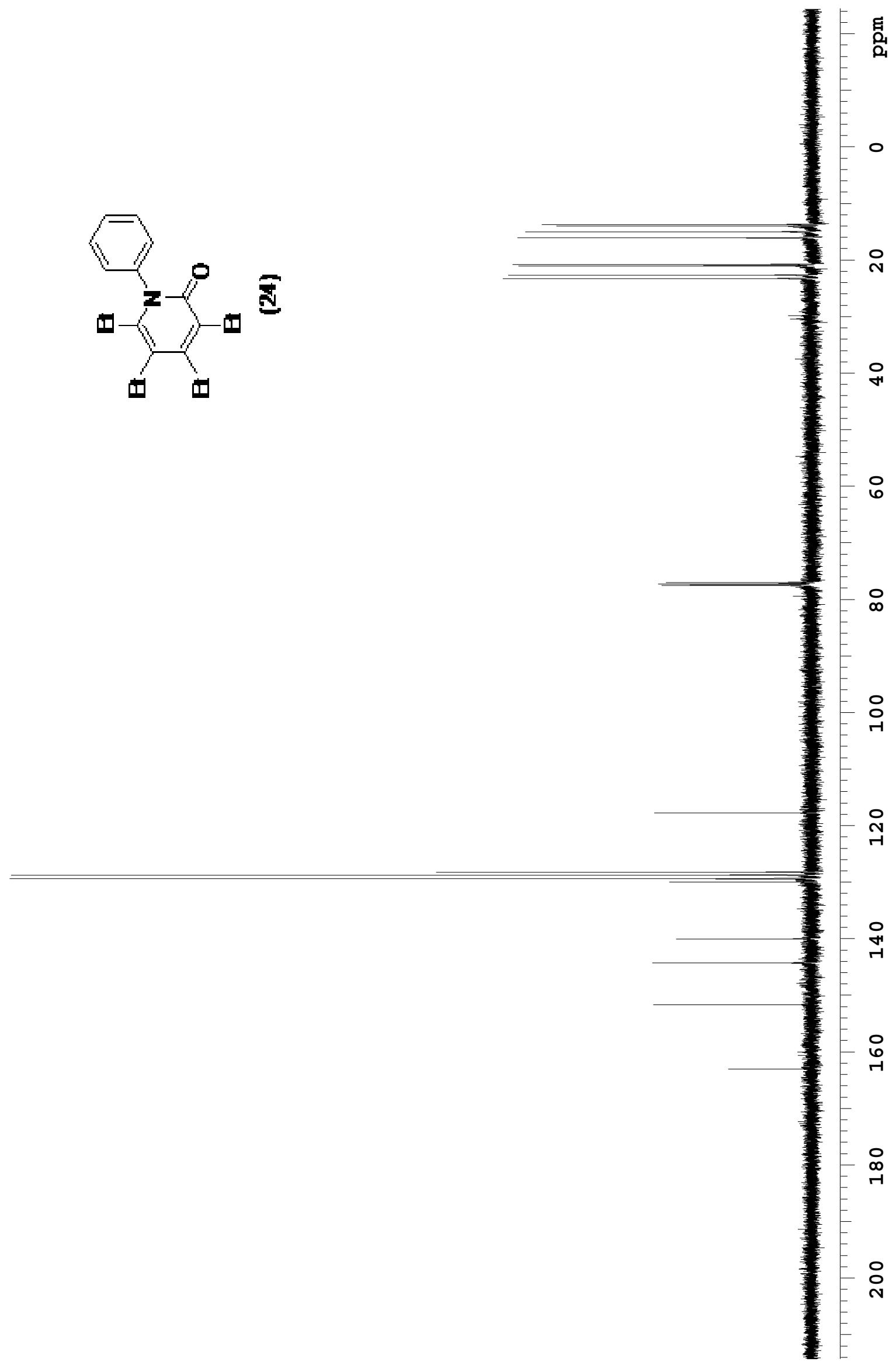

S35 